Article

\title{
Land Surface Temperature Retrieval from MODIS Data by Integrating Regression Models and the Genetic Algorithm in an Arid Region
}

\author{
Ji Zhou ${ }^{1,2, *}$, Xu Zhang ${ }^{1}$, Wenfeng Zhan ${ }^{3}$ and Huailan Zhang ${ }^{1}$
}

1 School of Resources and Environment, University of Electronic Science and Technology of China, Chengdu 611731, China; E-Mails: xuzhang@uestc.edu.cn (X.Z.); zhl2226567@ sina.cn (H.Z.)

2 State Key Laboratory for Remote Sensing Science, Beijing Normal University and Institute of Remote Sensing and Digital Earth, Chinese Academy of Sciences, Beijing 100875, China

3 Jiangsu Provincial Key Laboratory of Geographic Information Science and Technology, International Institute for Earth System Science, Nanjing University, Nanjing 210093, China; E-Mail: zhanwenfeng@ foxmail.com

* Author to whom correspondence should be addressed; E-Mail: jzhou233@ uestc.edu.cn; Tel./Fax: +86-28-6183-1571.

Received: 26 March 2014; in revised form: 20 May 2014 / Accepted: 3 June 2014 / Published: 10 June 2014

\begin{abstract}
The land surface temperature (LST) is one of the most important parameters of surface-atmosphere interactions. Methods for retrieving LSTs from satellite remote sensing data are beneficial for modeling hydrological, ecological, agricultural and meteorological processes on Earth's surface. Many split-window (SW) algorithms, which can be applied to satellite sensors with two adjacent thermal channels located in the atmospheric window between $10 \mu \mathrm{m}$ and $12 \mu \mathrm{m}$, require auxiliary atmospheric parameters (e.g., water vapor content). In this research, the Heihe River basin, which is one of the most arid regions in China, is selected as the study area. The Moderate-resolution Imaging Spectroradiometer (MODIS) is selected as a test case. The Global Data Assimilation System (GDAS) atmospheric profiles of the study area are used to generate the training dataset through radiative transfer simulation. Significant correlations between the atmospheric upwelling radiance in MODIS channel 31 and the other three atmospheric parameters, including the transmittance in channel 31 and the transmittance and upwelling radiance in channel 32, are trained based on the simulation dataset and formulated with three regression models. Next, the genetic algorithm is used to estimate the LST. Validations of the RM-GA method are based on the simulation dataset generated from in situ measured radiosonde profiles
\end{abstract}


and GDAS atmospheric profiles, the in situ measured LSTs, and a pair of daytime and nighttime MOD11A1 products in the study area. The results demonstrate that RM-GA has a good ability to estimate the LSTs directly from the MODIS data without any auxiliary atmospheric parameters. Although this research is for local application in the Heihe River basin, the findings and proposed method can easily be extended to other satellite sensors and regions with arid climates and high elevations.

Keywords: land surface temperature (LST); regression model; genetic algorithm; MODIS

\section{Introduction}

As one of the most important parameters of surface-atmosphere interactions, land surface temperature (LST) plays a crucial role in modeling hydrological, ecological, agricultural and meteorological processes on Earth's surface [1,2]. Thermal remote sensing data can be used to retrieve the spatially distributed LSTs by measuring the upward longwave radiation from the land surface under clear-sky conditions. The thermal signal acquired by a remote sensor at the top of the atmosphere (TOA) is influenced by surface parameters, e.g., temperature and land surface emissivity (LSE). In addition, the atmosphere is another important factor influencing the thermal signal at the satellite level, due to the atmospheric temperature and concentration of absorbents, such as water vapor, carbon dioxide, nitrogen oxide, ozone oxide, methane and carbon monoxide [3]. Therefore, estimating the LST from satellite data is not an easy task and has attracted the attention of scientists over the past several decades.

The LST is independent of the wavelength. The derivation of LST would be straightforward if the atmospheric profile and LSEs were collected while acquiring the remote sensing image. In this case, the atmospheric profile, which can be derived from a radiosonde, provides detailed vertical distributions of the temperature, humidity, pressure, and atmospheric contents in aerosols and molecular gases. Atmospheric effects can be quantified with atmospheric radiative transfer models and eliminated from the TOA spectral radiances of the remote sensing image. Next, the LST can be calculated from the surface radiances by taking the inverse of Planck's function with the LSE and the effective wavelength of the corresponding thermal channel.

The simultaneous atmospheric profile and in situ measurements of LSEs corresponding to the remote sensing image are often unavailable. The influences of the LSE and atmospheric effects are commonly treated separately. The LSE influences the TOA spectral radiance by reducing surface-emitted and reflected radiances. Anisotropy of reflectivity and emissivity may also reduce or increase the total radiance from the surface [4]. The emissivity of a surface is controlled by factors such as water content, chemical composition, structure, roughness, and the observation conditions [5]. Therefore, the LSE and LST must be estimated simultaneously. To achieve this goal, a number of temperature and emissivity separation (TES) algorithms have been developed for multispectral thermal infrared data [6-8]. These TES algorithms require the challenging task of calculating the land-leaving radiance after compensating for atmospheric absorption and path radiance based on radiative transfer simulation with the necessary atmospheric parameters (i.e., temperature, water vapor, ozone and 
aerosols) [7]. In fact, LSE is often assumed to be either constant or estimated based on empirical knowledge in practical applications [5,9].

To correct the atmospheric influences, split-window (SW) algorithms are commonly applied to remote sensing images acquired by two adjacent thermal channels located in the atmospheric window between $10 \mu \mathrm{m}$ and $12 \mu \mathrm{m}$. The basis of the SW algorithm lies in the different atmospheric absorptions of the two channels. Assuming that the LSE has been estimated, the LST can be retrieved using the SW algorithm. During the past four decades, a number of SW algorithms have been proposed for thermal remote sensing images acquired by the Advanced Very High-Resolution Radiometer (AVHRR) and MODIS instruments. Some of these SW algorithms are listed in Table 1 [10-23]. A thorough review of these algorithms can be found in [1].

Table 1. Split-Window (SW) algorithms published by studies in recent decades.

\begin{tabular}{|c|c|c|}
\hline No. & SW Algorithm & Reference \\
\hline 1 & $T_{\mathrm{s}}=A_{0}+A_{1} T_{11}+A_{2}\left(T_{11}-T_{12}\right)$ & Ottlé and Vidal-Madjar (1992) [10] \\
\hline 2 & $T_{\mathrm{s}}=A_{0}+A_{1} T_{11}+A_{2}\left(T_{11}-T_{12}\right)+A_{3}\left(T_{11}-T_{12}\right)^{2}$ & François and Ottlé (1996) [11] \\
\hline 3 & $T_{\mathrm{s}}=A_{0}+A_{1} T_{11}+A_{2}\left(T_{11}-T_{12}\right)+A_{3} T_{11} \varepsilon_{11}+A_{4}\left(T_{11}-T_{12}\right)\left(1-\varepsilon_{11}\right)+A_{5} T_{12} \Delta \varepsilon$ & Price (1984) [12] \\
\hline 4 & $T_{\mathrm{s}}=A_{0}+A_{1} T_{11}+A_{2}\left(T_{11}-T_{12}\right)+A_{3}(1-\varepsilon)$ & Ulivieri and Cannizzaro (1985) [13] \\
\hline 5 & $T_{\mathrm{s}}=A_{0}+\left(A_{1}+A_{2} \frac{1-\varepsilon}{\varepsilon}+A_{3} \frac{\Delta \varepsilon}{\varepsilon^{2}}\right)\left(T_{11}+T_{12}\right)+\left(A_{4}+A_{5} \frac{1-\varepsilon}{\varepsilon}+A_{6} \frac{\Delta \varepsilon}{\varepsilon^{2}}\right)\left(T_{11}-T_{12}\right)$ & $\begin{array}{c}\text { Becker and Li (1990) [14], } \\
\text { Wan and Dozier (1996) [15] }\end{array}$ \\
\hline 6 & $T_{\mathrm{s}}=A_{0}+A_{1} \frac{T_{11}-T_{0}}{\varepsilon_{11}}+A_{2} \frac{T_{12}-T_{0}}{\varepsilon_{12}}+A_{3} \frac{1-\varepsilon_{11}}{\varepsilon_{11}}+T_{0}$ & Prata and Platt (1991) [16] \\
\hline 7 & $T_{\mathrm{s}}=A_{0}+A_{1} T_{11}+A_{2}\left(T_{11}-T_{12}\right)+A_{3} \frac{1-\varepsilon}{\varepsilon}+A_{4} \frac{\Delta \varepsilon}{\varepsilon}$ & Vidal (1991) [17] \\
\hline 8 & $T_{\mathrm{s}}=A_{0}+A_{1} T_{11}+A_{2}\left(T_{11}-T_{12}\right)+A_{3}(1-\varepsilon)+A_{4} \Delta \varepsilon$ & Ulivieri et al. (1994) [18] \\
\hline 9 & $T_{\mathrm{s}}=A_{0}+\left(A_{1} w+A_{2} w^{2}+A_{3}\right) T_{11}+\left(A_{4} w+A_{5} w^{2}+A_{6}\right) T_{12}+A_{7} w+A_{8} w^{2}$ & François and Ottlé (1996) [11] \\
\hline 10 & $\begin{aligned} T_{\mathrm{s}}= & A_{0}+A_{1} T_{11}+\left[A_{2} w+A_{3}+\left(A_{4} w+A_{5}\right)\left(1-\varepsilon_{11}\right)+\left(A_{6} w+A_{7}\right) \Delta \varepsilon\right]\left(T_{11}-T_{12}\right) \\
& +\frac{1-\varepsilon_{11}}{\varepsilon_{11}} T_{11}\left[A_{8} w+A_{9}+\left(A_{10} w+A_{11}\right) \Delta \varepsilon\right] \\
& -\frac{1-\varepsilon_{12}}{\varepsilon_{12}} T_{12}\left[A_{12} w+A_{13}+\left(A_{14} w+A_{15}\right) \Delta \varepsilon\right]\end{aligned}$ & Sobrino et al. (1991) [19] \\
\hline 11 & $T_{\mathrm{s}}=A_{0}+A_{1} T_{11}+\left(A_{2} w+A_{3}\right)\left(T_{11}-T_{12}\right)+\left(A_{4} w+A_{5}\right)(1-\varepsilon)+\left(A_{6} w+A_{7}\right) \Delta \varepsilon$ & Ulivieri et al. (1994) [18] \\
\hline 12 & $\begin{aligned} T_{\mathrm{s}}= & A_{0}+A_{1} T_{11}+A_{2}\left(T_{11}-T_{12}\right)+A_{3}\left(T_{11}-T_{12}\right)^{2} \\
& +\left[\left(A_{4} w+A_{5}\right) T_{11}+\left(A_{6} w+A_{7}\right)\right](1-\varepsilon)-\left[\left(A_{8} w+A_{9}\right) T_{11}+\left(A_{10} w+A_{11}\right)\right] \Delta \varepsilon\end{aligned}$ & Coll et al. (1994) [20] \\
\hline 13 & $\begin{aligned} T_{\mathrm{s}}= & A_{0}+A_{1} T_{11}+A_{2}\left(T_{11}-T_{12}\right)+A_{3}\left(T_{11}-T_{12}\right)^{2} \\
& +\left(A_{4} w+A_{5}\right)(1-\varepsilon)-\left(A_{6} w+A_{7}\right) \Delta \varepsilon\end{aligned}$ & Sobrino and Raissouni (2000) [21] \\
\hline 14 & $T_{\mathrm{s}}=A_{0}+A_{1} T_{11}+A_{2}\left(T_{11}-T_{12}\right)+A_{3}\left(T_{11}-T_{12}\right)^{2}+\left(A_{4} w+A_{5}\right)(1-\varepsilon)$ & $\mathrm{Ma}(2003)[22]$ \\
\hline 15 & $\begin{aligned} T_{\mathrm{s}}= & A_{0}+A_{1} w+\left[A_{2}+\left(A_{3} w \cos \theta+A_{4}\right)\left(1-\varepsilon_{11}\right)-\left(A_{5} w+A_{6}\right) \Delta \varepsilon\right]\left(T_{11}+T_{12}\right) \\
& +\left[A_{7}+A_{8} w+\left(A_{9}+A_{10} w\right)\left(1-\varepsilon_{11}\right)-\left(A_{11} w+A_{12}\right) \Delta \varepsilon\right]\left(T_{11}-T_{12}\right)\end{aligned}$ & Becker and Li (1995) [23] \\
\hline
\end{tabular}

Note: $T_{\mathrm{S}}$ is the LST; $T_{11}$ and $T_{12}$ represent the TOA brightness temperatures in the $11 \mu \mathrm{m}$ and $12 \mu \mathrm{m}$ channels, respectively; $\varepsilon_{11}$ and $\varepsilon_{12}$ are the corresponding LSEs, respectively; $\varepsilon$ and $\Delta \varepsilon$ are the average value and mean value of $\varepsilon_{11}$ and $\varepsilon_{12}$, respectively; $\theta$ is the view zenith angle of the thermal sensor; $T_{0}$ is $273.15 \mathrm{~K}$; $w$ is the atmospheric water vapor content; and $A_{i}$ is the coefficient. 
Many SW algorithms emphasize the correction of atmospheric effects by decreasing the number of unknown parameters relating to the atmospheric state in the atmospheric radiative transfer equations (RTEs). This is accomplished by introducing other auxiliary parameters. Examinations of the SW algorithms for AVHRR and MODIS data reveal that many algorithms relate the atmospheric state to the atmospheric water vapor content, as shown in Table 1. Water vapor is the most important atmospheric component that influences radiance transfer in the thermal infrared range, and it is correlated with the atmospheric upwelling radiance, downwelling radiance, and transmittance [24,25]. Therefore, the SW algorithms' performance strongly depends on accurate determination of the water vapor content [26,27]. The atmospheric water vapor content may be inferred from radiosonde profiles and the Global Positioning System (GPS) or estimated from in situ measurements of meteorological parameters at the ground surface using empirical equations [28-30]. However, radiosonde profiles are often unavailable, and in situ measurements cannot provide spatially distributed water vapor content over large areas. It is possible to estimate the water vapor content from remote sensing images $[31,32]$. However, there are many uncertainties with the satellite-derived water vapor product, especially with respect to nighttime data. Another possible routine for reducing the number of unknown parameters in the RTEs of adjacent thermal channels is based on correlations between the channel-integrated atmospheric parameters. Because the representative atmospheric parameters at each channel highly depend on one another, the linear or nonlinear relationship can be expressed analytically, thereby assisting the user in solving the RTEs [33].

In this research, an arid region in northwestern China is selected as the study area, and MODIS is selected as a test case. The relationships between the atmospheric parameters in MODIS thermal channels 31 and 32 are investigated. A simple RM-GA (regression model-genetic algorithm) method for retrieving LST from the at-sensor spectral radiances of MODIS channels 31 and 32 is proposed. The main advantage of this method is that no auxiliary atmospheric parameter is required. The RM-GA method is validated. The possibility for its extension to other regions and thermal sensors and its possible applications are discussed.

\section{Methodology}

\subsection{Study Area and Datasets}

The study area, the Heihe River basin, is located in northwestern China (Figure 1). The Heihe River is the most important inland river in northwestern China. The Heihe River basin has an elevation higher than $1000 \mathrm{~m}$ and an arid climate with low atmospheric water vapor content [34]. It is one of the most arid regions in China. The land surface processes in the study area are important components of many field experiments, such as the HEIhe basin Field Experiment (HEIFE) [35]. The Watershed Allied Telemetry Experimental Research (WATER), which was a simultaneous remote sensing and ground-based experiment, was conducted in the study area from March to July of 2008. The overall objectives of this field experiment were to improve the understanding of hydrological and related ecological processes on a catchment scale, to accumulate a comprehensive dataset for the development of watershed science, and to promote the applicability of quantitative remote sensing in watershed science studies [36]. 
Figure 1. Location of the study area in mainland China.

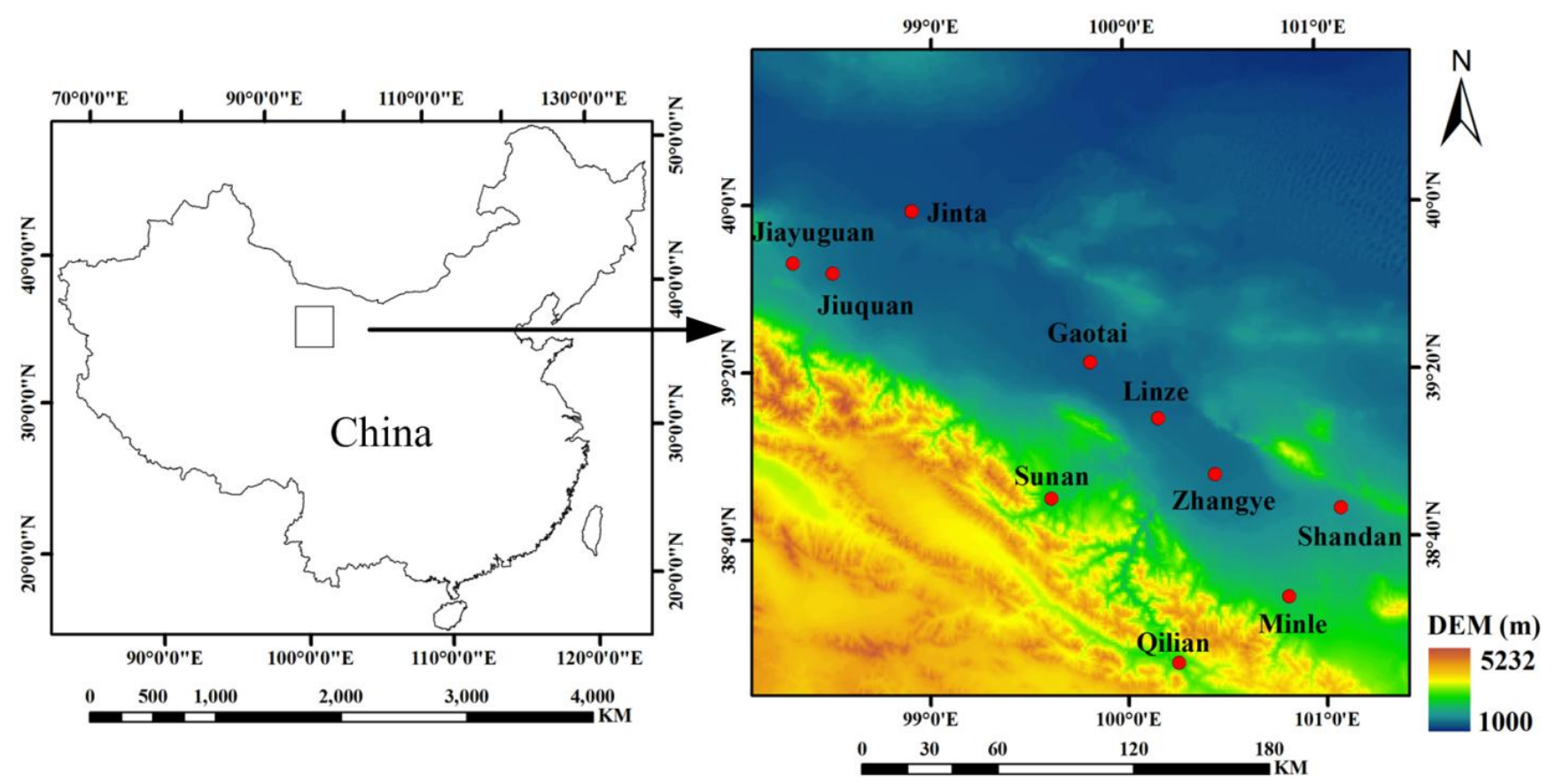

Atmospheric profiles are necessary to investigate the radiative transfer between the Sun-target-sensor paths. Eighteen radiosonde profiles under clear-sky conditions were collected in the study area during the field experiment from March to July of 2008. These radiosonde profiles covered elevations ranging from $1360 \mathrm{~m}$ to $3414 \mathrm{~m}$ and atmospheric water vapor contents ranging from $0.098 \mathrm{~g} \cdot \mathrm{cm}^{-2}$ to $1.706 \mathrm{~g} \cdot \mathrm{cm}^{-2}$. The March radiosonde profiles represented dry and cold weather, whereas those acquired in July represented relatively humid and warm weather. Outputs of the Global Data Assimilation System (GDAS) were also collected for examining the atmospheric parameters in the study area. GDAS is one of the operational systems of the National Weather Service's National Center for Environmental Prediction (NCEP). It is run four times per day (at 00, 06, 12, and 18 UTC), and the outputs include geopotential height, atmospheric temperature at 26 fixed pressure levels and relative humidity at 21 levels. The output is in GRIB (GRIdded Binary) format and extends from $\left(0 \mathrm{~W}, 90^{\circ} \mathrm{S}\right)$ to $\left(1^{\circ} \mathrm{W}, 90^{\circ} \mathrm{N}\right)$, with $1^{\circ} \times 1^{\circ}$ spatial resolution. Publications have reported that GDAS outputs yield advantages for applications such as atmospheric correction of thermal infrared remote sensing images [37], at-sensor signal simulation with radiative transfer models [38], and calibration of thermal remote sensors [39]. Four grids located in the study area, including $\left(100^{\circ} \mathrm{E}, 38^{\circ} \mathrm{N}\right),\left(100^{\circ} \mathrm{E}, 39^{\circ} \mathrm{N}\right)$, $\left(98^{\circ} \mathrm{E}, 40^{\circ} \mathrm{N}\right)$, and $\left(99^{\circ} \mathrm{E}, 40^{\circ} \mathrm{N}\right)$, were selected to extract the atmospheric profiles. The temporal coverage of the extracted GDAS atmospheric profiles spans January to December 2008. Finally, 422 GDAS atmospheric profiles under clear-sky conditions were extracted to establish the prior knowledge database of the atmospheric state in the study area.

In situ LST measurements were collected near the Biandukou site (location: $100.97^{\circ} \mathrm{E}, 38.27^{\circ} \mathrm{N}$; elevation: $2690 \mathrm{~m}$ ). The land surface at the this site was homogenous during the field experiment, and the dominating land cover type was bare cropland covered by soil and sparse barley straws, as well as some meadows with dry grasses. Simultaneous filed measurements were conducted on 14 March 2008, for comparing the measured LSTs with the LSTs provided by the Terra and Aqua MODIS. Two key areas were selected to collect the ground truths of the LSTs. The locations of these two key areas were 
$\left(100.98^{\circ} \mathrm{E}, 38.22^{\circ} \mathrm{N}\right)$ and $\left(100.97^{\circ} \mathrm{E}, 38.26^{\circ} \mathrm{N}\right)$. Both of these two key areas were homogenous with bare soil. The key areas and their surrounding areas were homogenous. The size of each key area was set at 120 by $120 \mathrm{~m}$, and each key area was divided into 16 sub-areas with 30 by $30 \mathrm{~m}$ sizes.

During the daytime on 14 March 2008, the overpassing times of the Terra and Aqua satellites were 04:30 and 06:10 (UTC). While the satellites were overpassing, the radiative temperature at the center of each sub-area was measured using Testo handheld infrared thermometers (IRT). The wavelength range of this instrument is $8 \mu \mathrm{m}$ to $14 \mu \mathrm{m}$. The temperature range is $-35.0{ }^{\circ} \mathrm{C}$ to $950.0{ }^{\circ} \mathrm{C}$, and the precision is $\pm 0.75{ }^{\circ} \mathrm{C}$ in the temperature range of $-35.0{ }^{\circ} \mathrm{C}$ to $75.0^{\circ} \mathrm{C}$. Next, the radiative temperatures within a key area were averaged to denote the radiative temperature of the key area. The measured surface radiative temperatures with IRT were converted to the surface temperatures after correcting the broadband emissivity and atmospheric influences. Due to the lack of instruments for measuring the surface emissivities, the broadband emissivity of bare soil was assumed to be 0.950 . Details about the conversion of radiative temperatures to surface temperatures can be found in [40].

\subsection{Regression Models for Atmospheric Parameters}

The construction of this method involves three stages. In the first stage, the radiative transfer equations of MODIS channels 31 and 32 are simplified. In the second stage, the GDAS atmospheric profiles are used to simulate channel-integrated atmospheric parameters in MODIS channels 31 and 32 based on the MODTRAN4 code [41]. Regression models that describe the relationships between these parameters are developed. In the third stage, new radiative transfer equations are established by substituting the regression models into the simplified radiative transfer equations. The LST is calculated with the genetic algorithm through iteration and optimization processes.

The radiative transfer equation (RTE) in the thermal infrared range is based on the following assumptions [3,42]: (1) the atmosphere is at local thermodynamic equilibrium; (2) no scattering occurs, and thus only cloud-free and non-hazy conditions are considered; and (3) the target is a Lambertian surface. Assuming that the land is a Lambertian surface in the thermal infrared range, the radiative transfer process from the ground to the remote sensor can be described as Equation (1) [43]:

$$
L_{\lambda}=\varepsilon_{\lambda} \tau_{\lambda} B\left(\lambda, T_{\mathrm{s}}\right)+\left(1-\varepsilon_{\lambda}\right) \tau_{\lambda} L_{\lambda}^{\downarrow}+L_{\lambda}^{\uparrow}
$$

where $\lambda$ is the wavelength; $L_{\lambda}$ is the TOA radiance; $\varepsilon_{\lambda}$ is the surface emissivity; $\tau_{\lambda}$ is the total transmittance of the atmosphere; $B\left(\lambda, T_{\mathrm{s}}\right)$ is the radiance emitted by a blackbody at temperature $T_{\mathrm{s}}$; and $L_{\lambda}^{\downarrow}$ and $L_{\lambda}^{\uparrow}$ are the atmospheric downwelling and upwelling radiance, respectively.

$B\left(\lambda, T_{\mathrm{s}}\right)$ can be calculated using Planck's function, but deriving an operative expression of the temperature is complex, and the function should be simplified. Applying Taylor's approximation of radiance around a certain temperature value or linearization is a commonly used method [20,44]. We calculated the channel-integrated radiances of MODIS channels 31 and 32 in the temperature range of $250.0 \mathrm{~K}$ to $340.0 \mathrm{~K}$, with a temperature increment of $0.5 \mathrm{~K}$, according to the variability of LST in the study area. Then, the relationships between temperature and radiance in these two thermal channels were investigated. A significant linear relationship was found between the radiance and the temperature. Six linear functions are proposed to replace Planck's functions of MODIS channels 31 and 32 in three temperature ranges. These linear functions follow the general form: 


$$
B_{i}(T)=a_{i} T+b_{i}
$$

where $i=31,32 ; B_{i}$ is the radiance in channel $i ; T$ is temperature; and $a_{i}$ and $b_{i}$ are coefficients. The values $a_{i}, b_{i}$, and the parameters of regression analysis are listed in Table 2. Equation (2) can also be extended to other areas because the radiance only depends on the temperature and the effective wavelength of the thermal channel.

Table 2. Coefficients for linearizing Planck's functions of MODIS channels 31 and 32 in different temperature ranges. The parameters for regression analysis are also shown.

\begin{tabular}{cccccccc}
\hline Temperature Range & MODIS Channel & $\boldsymbol{a}$ & $\boldsymbol{b}$ & Adjusted $\boldsymbol{R}^{\mathbf{2}}$ & Significance Level & Sample Size \\
\hline \multirow{2}{*}{$250 \mathrm{~K}-280 \mathrm{~K}$} & 31 & 0.1003 & -21.175 & 0.998 & 0.001 & 61 \\
& 32 & 0.0902 & -18.637 & 0.998 & 0.001 & 61 \\
\hline \multirow{2}{*}{$280 \mathrm{~K}-310 \mathrm{~K}$} & 31 & 0.1350 & -30.917 & 0.999 & 0.001 & 60 \\
& 32 & 0.1169 & -26.110 & 0.999 & 0.001 & 60 \\
\hline \multirow{2}{*}{$310 \mathrm{~K}-340 \mathrm{~K}$} & 31 & 0.1693 & -41.560 & 0.999 & 0.001 & 60 \\
\hline
\end{tabular}

In Equation (1), the atmospheric upwelling radiance $L_{\lambda}^{\uparrow}$ is usually computed as [45]:

$$
L_{\lambda}^{\uparrow}=\int_{0}^{z} B_{\lambda}\left(T_{z}\right) \frac{\partial \tau_{\lambda}(\theta, z, Z)}{\partial z} d z
$$

where $Z$ is the altitude of the remote sensor; $T_{z}$ is the atmospheric temperature at altitude $z$; and $\tau_{\lambda}(\theta, z, Z)$ is the upwelling atmospheric transmittance from altitude $z$ to the sensor height $Z$. After employing the mean value theorem to express the upwelling radiance, $L_{\lambda}^{\uparrow}$ can be expressed as [46]:

$$
L_{\lambda}^{\uparrow}=\left[1-\tau_{\lambda}(\theta)\right] B_{\lambda}\left(T_{\mathrm{a}}\right)
$$

where $T_{\mathrm{a}}$ is the effective mean atmospheric temperature.

With a similar simplification, $L_{\lambda}^{\downarrow}$ can be calculated as:

$$
L_{\lambda}^{\downarrow}=\left[1-\tau_{\lambda}(\theta)\right] B_{\lambda}\left(T_{\mathrm{a}}^{\downarrow}\right)
$$

where $T_{\mathrm{a}}^{\downarrow}$ is the average temperature of the atmospheric downwelling radiance. Qin et al. (2001) concluded that using $T_{\mathrm{a}}$ to replace $T_{\mathrm{a}}^{\downarrow}$ in Equation (5) does not have much influence on the accuracy of the retrieved LST [46]. Therefore, it is reasonable to use $L_{\lambda}^{\uparrow}$ replace $L_{\lambda}^{\downarrow}$. Consequently, the channel-integrated thermal radiances acquired by MODIS channels 31 and 32 at TOA can be described as follows:

$$
L_{i}=\varepsilon_{i} \tau_{i} B_{i}\left(T_{\mathrm{s}}\right)+\left[1+\left(1-\varepsilon_{i}\right) \tau_{i}\right] L_{i}^{\uparrow}
$$

The parameters in Equation (6) have the same meanings as those in Equation (1), and the subscript $i$ means that the parameters are for MODIS channels 31 or 32. According to the correlations between atmospheric radiations in adjacent thermal channels of a sensor, it is reasonable to assume that the atmospheric parameters, including $\tau_{31}, L_{31}^{\uparrow}, \tau_{32}$, and $L_{32}^{\uparrow}$, can be expressed as functions of a single parameter. Therefore, radiative transfer simulations are conducted to analyze the relationships between these atmospheric parameters. The extracted atmospheric profiles from the described GDAS datasets are put into the MODTRAN4 code to simulate the TOA radiances and other atmospheric parameters. 
It should be noted that the altitude, pressure, air temperature, and humidity at each layer of each atmospheric profile are used here. The radiative transfer simulations follow these conditions: (1) the MODTRAN4 code is executed in the thermal radiance mode; (2) the sensor view zenith angles in MODTRAN4 are set to range from $0^{\circ}$ to $60^{\circ}$ in $5^{\circ}$ increments to cover the view angles of MODIS; and (3) the sky is clear, and the visibility is $23 \mathrm{~km}$. The water vapor content along the atmospheric path can be extracted from MODTRAN4 outputs. The simulated parameters are converted to the channel-integrated values following [47]:

$$
<x>=\frac{\int_{\lambda_{\min }}^{\lambda_{\max }} x(\lambda) f(\lambda) d \lambda}{\int_{\lambda_{\min }}^{\lambda_{\max }} f(\lambda) d \lambda}
$$

where $\langle x\rangle$ is the channel-integrated value of the parameter $x ; \lambda_{\min }$ and $\lambda_{\max }$ are the lower and upper wavelengths of the corresponding channels; $x(\lambda)$ is the value of parameter $x$ at wavelength $\lambda$; and $f(\lambda)$ is the spectral response function.

In total, 5486 samples covering 13 zenith angles for all GDAS atmospheric profiles are used to analyze the relationships between $\tau_{31}, \tau_{32}, L_{31}^{\uparrow}$ and $L_{32}^{\uparrow}$. The scatter plots between $L_{31}^{\uparrow}$ and the other three parameters are displayed in Figure 2. Regression analysis reveals that $\tau_{31}$ and $\tau_{32}$ can be linearly parameterized by $L_{31}^{\uparrow}$ with sufficient accuracy, and $L_{32}^{\uparrow}$ can be estimated by $L_{31}^{\uparrow}$ with a quadric function. The adjusted $R^{2}$ values used to establish the regressions between $\tau_{31}, \tau_{32}, L_{32}^{\uparrow}$ and $L_{31}^{\uparrow}$ are $0.990,0.988$, and 1.0, respectively. All the correlations are significant at the 0.001 probability level. The formula is listed below:

$$
\left[\begin{array}{c}
\tau_{31}\left(L_{31}^{\uparrow}\right) \\
\tau_{32}\left(L_{31}^{\uparrow}\right) \\
L_{32}^{\uparrow}\left(L_{31}^{\uparrow}\right)
\end{array}\right]=\left[\begin{array}{ccc}
0 & -0.136 & 0.988 \\
0 & -0.174 & 0.984 \\
-0.054 & 1.358 & -0.023
\end{array}\right]\left[\begin{array}{c}
L_{31}^{\uparrow} \\
L_{31}^{\uparrow} \\
1
\end{array}\right]
$$

Figure 2. Scatter plots between the atmospheric upwelling radiance of MODIS channel 31 and the other atmospheric parameters. (a) transmittances of channels 31 and 32; (b) upwelling radiance of channel 32 .

(a)

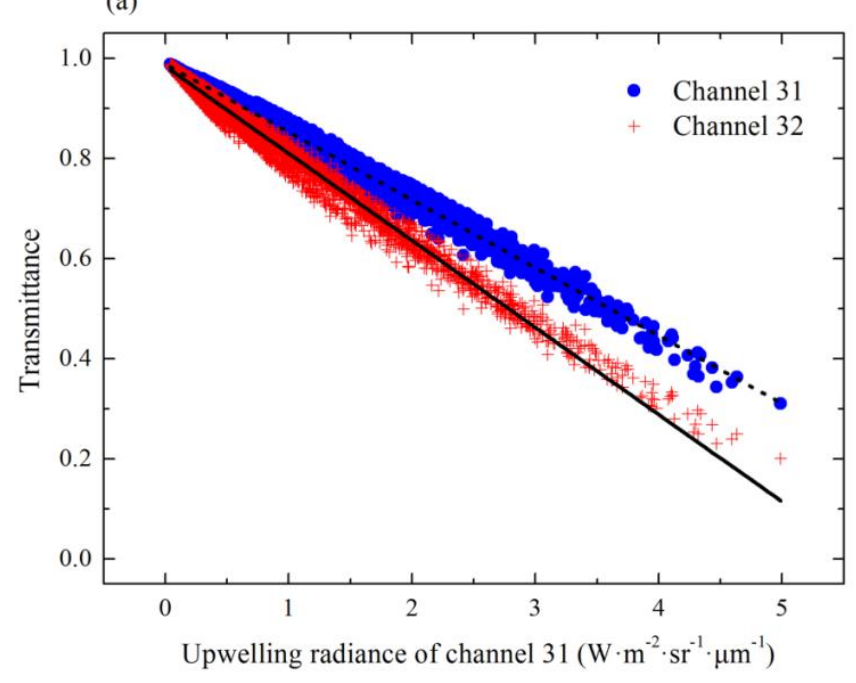

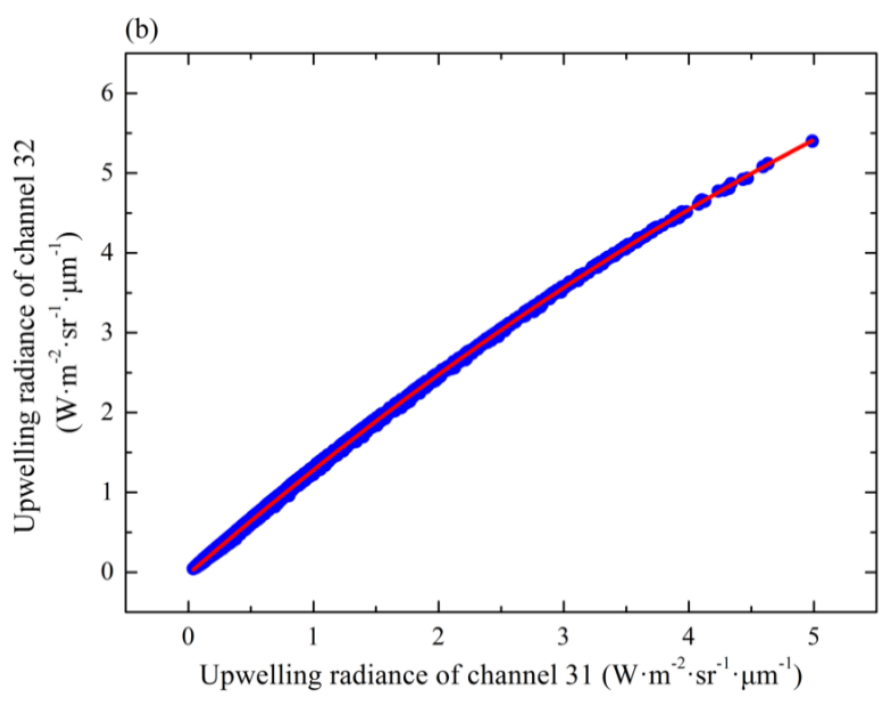


We use the eighteen radiosonde profiles collected during the field experiment to quantify the uncertainties of Equation (8). The simulated $L_{31}^{\uparrow}$ of all the radiosonde profiles based on the MODTRAN4 code are used to calculate $\tau_{31}, \tau_{32}$ and $L_{32}^{\uparrow}$ following Equation (8). Statistics on the errors of the calculated values, including the error ranges, standard deviations of the error and absolute error, mean absolute errors (MAEs), and root-mean-square errors (RMSEs), are presented in Table 3. Based on Table 3, it can be concluded that the regression models are highly accurate. Table 3 also demonstrates that the calculated $\tau_{32}$ has a slightly larger error than $\tau_{31}$ does because MODIS channel 32 suffers stronger significant atmospheric influences than channel 31 does.

Table 3. Statistics on the errors of the calculated $\tau_{31}, \tau_{32}$ and $L_{32}^{\uparrow}$ based on $L_{31}^{\uparrow}$ for the radiosonde profiles collected during the field experiment.

\begin{tabular}{cccccc}
\hline Parameter & Error Range & $\begin{array}{c}\text { Standard Deviation } \\
\text { of the Error }\end{array}$ & $\begin{array}{c}\text { Standard Deviation } \\
\text { of the Absolute Error }\end{array}$ & MAE & RMSE \\
\hline$\tau_{31}$ & $-0.0189-0.0042$ & 0.0059 & 0.0054 & 0.0080 & 0.0097 \\
$\tau_{32}^{-2}$ & $-0.0221-0.0035$ & 0.0044 & 0.0042 & 0.0098 & 0.0107 \\
$L_{32}^{\dagger}\left(\mathrm{W} \cdot \mathrm{m}^{-2} \cdot \mathrm{sr}^{-1} \cdot \mu \mathrm{m}^{-1}\right)$ & $-0.0144-0.0517$ & 0.0122 & 0.0098 & 0.0083 & 0.0128 \\
\hline
\end{tabular}

\subsection{Determination of LST with a Genetic Algorithm}

The genetic algorithm (GA) is a technique for searching and optimizing based on selection and natural genetics [48]. The basic principle of the GA is similar to natural selection and inheritance during biological evolution. It begins with a population that contains potential solutions. Then, an objective function is used to assess each potential solution. The solutions with good abilities are selected and inherited by the next generation. The other solutions are changed by mutation or crossover. The new potential solutions are assessed again with the objective function. The iteration process stops when the objective function reaches the defined threshold or the iteration time exceeds a pre-defined value. Compared with other optimization algorithms, the GA has a good ability for global optimization and does not trend to a local solution. The GA has a high probability of finding the global optimal solution even when the objective function has noise [49].

The GA can resolve ill-posed problems where there are more unknowns than equations. These ill-posed problems are common when retrieving parameters from remote sensing data. Xu et al. (2001) and Zhuang et al. (2001) reported instances where the GA was used to retrieve the component temperature from multi-angular thermal remote sensing images, and they concluded that the GA is a robust tool for estimating the component temperature [50,51]. Song and Zhao (2007) applied the GA to retrieve component temperature from MODIS data based on a linear spectral mixing model [52]. The GA appears to be a good method for retrieving the LST from thermal remote sensing images.

In the case where LSEs in MODIS channels 31 and 32 have been obtained, there are two unknowns left after substituting the regression models into the two RTEs. The unknown parameters are LST and $L_{31}^{\uparrow}$. It is straightforward to obtain their analytical solutions. If the LST is calculated directly from the two RTEs, the errors and noises of the parameters (e.g., LSEs) and regression models may lead to an unacceptable error in the LST. To obtain physically meaningful estimations, the variation ranges of LST and $L_{31}^{\uparrow}$ should be determined first to constrain the equation solutions. The GA is able to generate stable results and is not sensitive to the parameter errors or noises with the objective function $[49,50]$. 
Furthermore, the GA does not tend to generate local solutions for non-linear inversion problems. Although a disadvantage of using the GA for solving multi-dimensional problems is that it is time-consuming, the present problem that must be solved is positive definite, and the GA is efficient. Therefore, the GA algorithm in the Global Optimization Toolbox provided by the Matlab software is used here.

After replacing $\tau_{31}, \tau_{32}$, and $L_{32}^{\uparrow}$ in the RTEs of MODIS channels 31 and 32 with Equation (8), two new RTEs are obtained, as follows:

$$
\begin{gathered}
L_{31}=\varepsilon_{31} \tau_{31}\left(L_{31}^{\uparrow}\right) B_{31}\left(T_{\mathrm{s}}\right)+\left[1+\left(1-\varepsilon_{31}\right) \tau_{31}\left(L_{31}^{\uparrow}\right)\right] L_{31}^{\uparrow} \\
L_{32}=\varepsilon_{32} \tau_{32}\left(L_{31}^{\uparrow}\right) B_{32}\left(T_{\mathrm{s}}\right)+\left[1+\left(1-\varepsilon_{32}\right) \tau_{32}\left(L_{31}^{\uparrow}\right)\right] L_{32}^{\uparrow}\left(L_{31}^{\uparrow}\right)
\end{gathered}
$$

The configuration of GA for calculating LST from Equations (9) and (10) contains the following four steps:

(1) Defining the ranges of $L_{31}^{\uparrow}$ and $T_{\mathrm{s}}$ : The ranges of $L_{31}^{\uparrow}$ and $T_{\mathrm{s}}$ are defined as $0.01 \mathrm{~W} \cdot \mathrm{m}^{-2} \cdot \mathrm{sr}^{-1} \cdot \mu \mathrm{m}^{-1}$ to $3.0 \mathrm{~W} \cdot \mathrm{m}^{-2} \cdot \mathrm{sr}^{-1} \cdot \mu \mathrm{m}^{-1}$ and $250.0 \mathrm{~K}$ to $340.0 \mathrm{~K}$, respectively. The previous two ranges are set according to the conditions of the study area and our investigations of the radiosonde profiles, GDAS profiles, and MODIS LST/emissivity products. On the one hand, the maximum value of $L_{31}^{\dagger}$ calculated based on all the in situ atmospheric radiosondes is $1.8821 \mathrm{~W} \cdot \mathrm{m}^{-2} \cdot \mathrm{sr}^{-1} \cdot \mu \mathrm{m}^{-1}$, appearing in the region with low elevation in summer. For all the GDAS profiles, over $98 \%$ of the simulated samples have $L_{31}^{\uparrow}$ lower than $3.0 \mathrm{~W} \cdot \mathrm{m}^{-2} \cdot \mathrm{sr}^{-1} \cdot \mu \mathrm{m}^{-1}$, and the GDAS profiles are found to overestimate the water vapor contents. On the other hand, a range of $250.0 \mathrm{~K}$ to $340.0 \mathrm{~K}$ covers most possible conditions in the study area, according to our finding based on MODIS LST products of the study area.

(2) Defining the initial values of $T_{\mathrm{s}}$ and $L_{31}^{\uparrow}$ : Considering that the atmospheric effects in MODIS channel 32 are more significant than those in channel 31, the at-sensor brightness temperature of channel $31, T_{\mathrm{b} 31}$, is used as the initial value of $T_{\mathrm{s}}$. It is difficult to determine the initial value of $L_{31}^{\uparrow}$ because there is no knowledge about the atmospheric condition. However, we find that there is a significant correlation between $L_{31}^{\uparrow}$ and $T_{\mathrm{b} 31}-T_{\mathrm{b} 32}$ (see Figure 3 ). Their relationship can be written as:

$$
L_{31}^{\uparrow}=0.108\left(T_{\mathrm{b} 31}-T_{\mathrm{b} 32}\right)^{2}+0.758\left(T_{\mathrm{b} 31}-T_{\mathrm{b} 32}\right)+0.310
$$

In total, 5486 samples are used to infer Equation (11). The adjusted $R^{2}$ value of the regression is 0.964 , and the correlation is significant at the 0.001 probability level, demonstrating that Equation (11) is sufficiently accurate to calculate the initial value of $L_{31}^{\uparrow}$. Because of the searching and optimizing processes, the results generated by the GA are not significantly influenced by the initial values of the unknowns.

(3) Designing the objective function of GA: The estimated $T_{\mathrm{s}}$ and $L_{31}^{\uparrow}$ should balance the radiative transfer equations. Therefore, the following function is used as the objective function to select appropriate individuals during iteration:

$$
\begin{aligned}
F= & \left\{L_{31}-\varepsilon_{31} \tau_{31}\left(L_{31}^{\uparrow}\right) B_{31}\left(T_{\mathrm{s}}\right)-\left[1+\left(1-\varepsilon_{31}\right) \tau_{31}\left(L_{31}^{\uparrow}\right)\right] L_{31}^{\uparrow}\right\}^{2} \\
& +\left\{L_{32}-\varepsilon_{32} \tau_{32}\left(L_{31}^{\uparrow}\right) B_{32}\left(T_{\mathrm{s}}\right)-\left[1+\left(1-\varepsilon_{32}\right) \tau_{32}\left(L_{31}^{\uparrow}\right)\right] L_{32}^{\uparrow}\left(L_{31}^{\uparrow}\right)\right\}^{2}
\end{aligned}
$$

where the objective value, $F$, should be close to 0 . 
Figure 3. Scatter plot between the simulated atmospheric upwelling radiance in MODIS channel 31 and differences in the at-sensor brightness temperatures of channel 31 and $32\left(T_{\mathrm{b} 31}-T_{\mathrm{b} 32}\right)$.

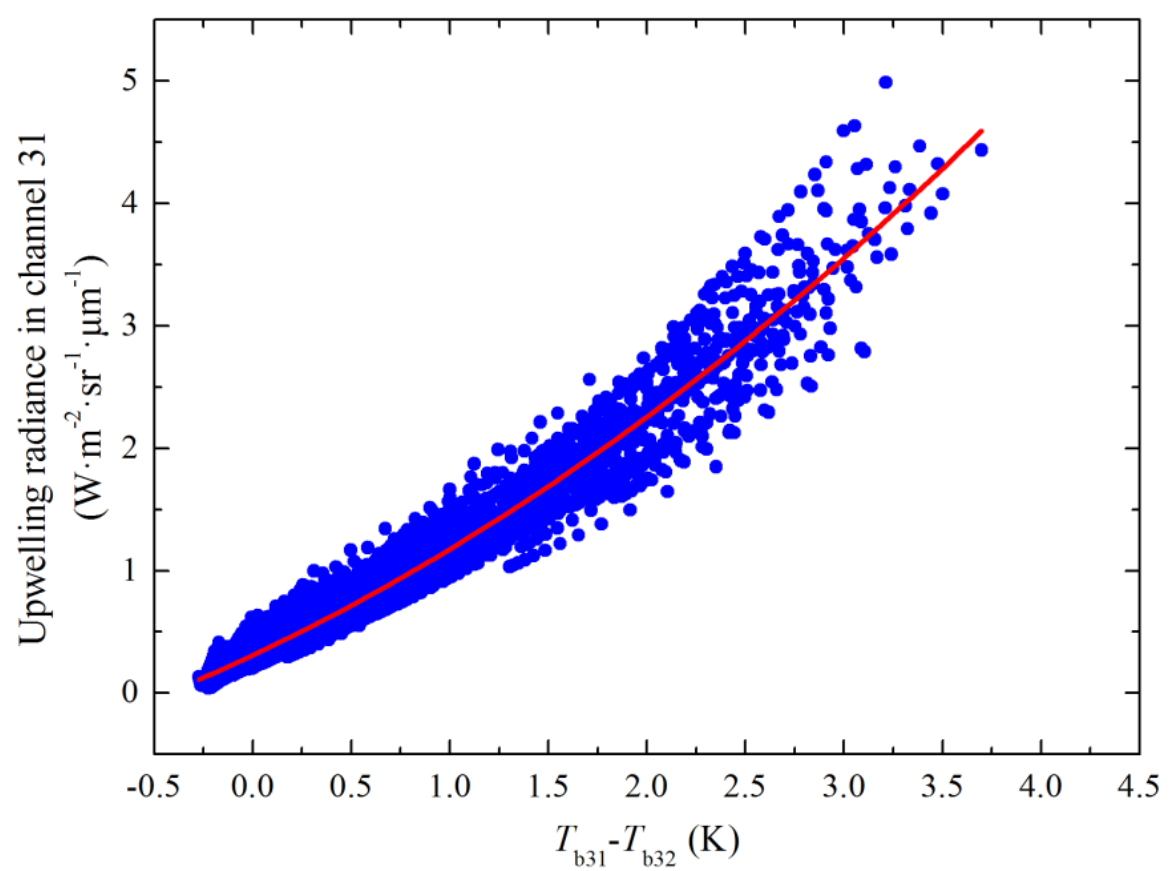

(4) Specifying the population size (Popsize), maximum number of generations (Maxgen), crossover fraction $(\mathrm{Pc})$ and mutation fraction $(\mathrm{Pm})$ : These parameters may significantly influence the optimization of GA [50-52]. Determining these parameters is a repetitive process. A group of parameters derived from the simulation of a radiosonde profile, which were acquired at the Biandukou site on 5 July 2008, is used for an experiment. These parameters are an LST of $300.9 \mathrm{~K}$, TOA spectral radiances of $9.3994 \mathrm{~W} \cdot \mathrm{m}^{-2} \cdot \mathrm{sr}^{-1} \cdot \mu \mathrm{m}^{-1}$ and $8.7839 \mathrm{~W} \cdot \mathrm{m}^{-2} \cdot \mathrm{sr}^{-1} \cdot \mu \mathrm{m}^{-1}$ for channels 31 and 32 , respectively.

First, Popsize is set to range from 10 to 90, and the Maxgen is set to range from 20 to 180. These two ranges are set by following the trial and error process. The GA is run five times for each Popsize and Maxgen pair, and the MAE of the retrieved LSTs is calculated (Table 4). Figure 4 shows example minimum, mean, and maximum objective values of all individuals in each generation during the iteration process. The LST error decreases when Popsize increases. Setting Maxgen as 100 and Popsize as 50 is a good timesaving choice. The convergence becomes very stable after the maximum number of generations reaches 100 .

Table 4. MAEs of the retrieved land surface temperatures with different population sizes and maximum generations in the genetic algorithm.

\begin{tabular}{cccccc}
\hline $\begin{array}{c}\text { Population Size } \\
\text { (Popsize) }\end{array}$ & \multicolumn{5}{c}{ Maximum Generation (Maxgen) } \\
\cline { 2 - 6 } & $\mathbf{2 0}$ & $\mathbf{6 0}$ & $\mathbf{1 0 0}$ & $\mathbf{1 4 0}$ & $\mathbf{1 8 0}$ \\
\hline 10 & 2.7 & 1.1 & 0.3 & 0.7 & 0.6 \\
30 & 0.3 & 0.4 & 0.5 & 0.3 & 0.3 \\
50 & 0.5 & 0.5 & 0.3 & 0.3 & 0.3 \\
70 & 0.4 & 0.4 & 0.3 & 0.3 & 0.3 \\
90 & 0.3 & 0.4 & 0.3 & 0.3 & 0.3 \\
\hline
\end{tabular}


Figure 4. The minimum (Min), mean (Mean), and maximum (Max) objective values of all the individuals in each generation during the iteration process.

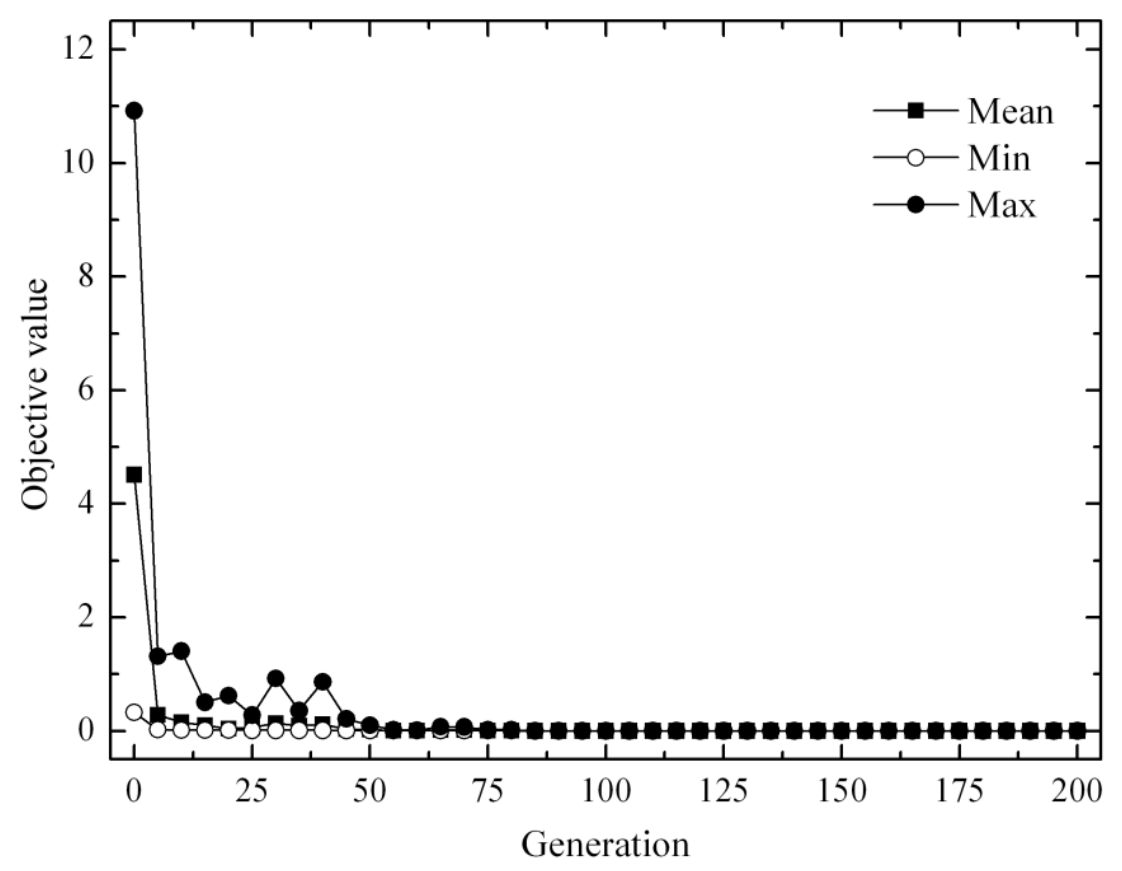

Second, we examine the determination of the mutation fraction and crossover fraction (Pc) of the GA. The GA uses the mutation and crossover functions to produce new individuals at each generation. In this research, Pm is set as "adaptive feasible" for constrained minimization, which randomly generates adaptive directions with respect to the last successful or unsuccessful generation. Pc is commonly set at 0.4 to 0.9 . A smaller value of Pc will limit the ability for an individual to mutate and find the global optimum, but a greater value will cause an unstable solution of the GA [52]. We chose values for Pc ranging from 0.4 to 0.9 with an increment of 0.1 and tested the GA five times for each Pc value. The errors of the calculated LSTs are listed in Table 5. Table 5 shows that the LST errors are 0.3 when the Pc is 0.4 to 0.8 . The LST error increases when Pc is 0.9. This phenomenon suggests that premature convergence occurs. The GA requires a relatively long time to converge when $\mathrm{Pc}$ is set to a smaller value. $\mathrm{Pc}$ is set to 0.8 in this research.

Table 5. Errors in the retrieved land surface temperatures with different crossover fractions in the genetic algorithm.

\begin{tabular}{ccccccc}
\hline \multirow{2}{*}{ Time } & \multicolumn{7}{c}{ Crossover Fraction $(\mathbf{P c})$} \\
\cline { 2 - 7 } & $\mathbf{0 . 4}$ & $\mathbf{0 . 5}$ & $\mathbf{0 . 6}$ & $\mathbf{0 . 7}$ & $\mathbf{0 . 8}$ & $\mathbf{0 . 9}$ \\
\hline 1 & 0.3 & 0.3 & 0.3 & 0.3 & 0.3 & 0.3 \\
2 & 0.3 & 0.3 & 0.3 & 0.3 & 0.3 & 0.4 \\
3 & 0.3 & 0.3 & 0.3 & 0.3 & 0.3 & 0.4 \\
4 & 0.3 & 0.3 & 0.3 & 0.3 & 0.3 & 0.3 \\
5 & 0.3 & 0.3 & 0.3 & 0.3 & 0.3 & 0.5 \\
\hline
\end{tabular}




\section{Sensitivity Analysis and Validations}

\subsection{Sensitivity Analysis}

Sensitivity analysis is important for developing the LST retrieval algorithms. Such analyses have been reported in publications, e.g., Becker and Li (1990) [14], Li and Becker (1993) [53], and Qin et al. (2001) [46]. Here, the sensitivities of the proposed RM-GA method to the errors of LSEs and at-sensor brightness temperatures of MODIS channels 31 and 32 are investigated because errors in these parameters may lead to errors in the LST. The LST error can be calculated as follows:

$$
\delta T_{\mathrm{s}}=\left|T_{\mathrm{s}}(x+\delta x)-T_{\mathrm{s}}(x)\right|
$$

where $\delta T_{\mathrm{s}}$ is the error in LST; $x$ is the parameter on which the sensitivity analysis is performed; and $\delta x$ is the error in $x$.

Four instances are considered in the sensitivity analysis including LST errors on $\delta \varepsilon_{31}, \delta \varepsilon_{32}, \delta T_{\mathrm{b} 31}$ and $\delta\left(T_{\mathrm{b} 31}-T_{\mathrm{b} 32}\right)$. Radiosonde profiles BG0314 and YK0707 are selected and put into the MODTRAN4 code to simulate the at-sensor spectral radiances of MODIS channels 31 and 32. Next, the simulations are used to estimate the LSTs using the RM-GA method. Radiosonde BG0314 was collected at the Biandukou site on 14 March 2008. It represented a cold and arid atmosphere. Radiosonde YK0707 was collected at the Yingke site, located at $100^{\circ} 25^{\prime} \mathrm{E}, 38^{\circ} 51^{\prime} \mathrm{N}$ and with an elevation of $1486 \mathrm{~m}$, on 7 July 2008. It represented hot and humid weather. For each profile, the sensitivity analysis is conducted at two view zenith angles (i.e., $0^{\circ}$ and $30^{\circ}$ ) for two land cover types (i.e., soil and vegetation). For soil, the LSEs are defined as 0.970 for MODIS channel 31 and channel 32; for vegetation, the LSEs are defined as 0.986 and 0.988 for these two channels. LST is set as the temperature of the bottom atmosphere layer for each profile.

LST errors, which are caused by LSE errors, for the two radiosonde profiles are presented in Tables 6 and 7. Sensitivity analysis reveals that underestimating the emissivity of MODIS channel 31 will cause the overestimation of LST, and vice versa. The sensitivity of LST on $\delta \varepsilon_{31}$ varies with atmospheric conditions. For the BG0314 profile, $\delta T_{\mathrm{s}}$ is up to $1.4 \mathrm{~K}$ when $\delta \varepsilon_{31}$ is 0.01 and up to $3.2 \mathrm{~K}$ when $\delta \varepsilon_{31}$ is 0.02 . For the YK0707 profile, $\delta T_{\mathrm{s}}$ is up to $3.1 \mathrm{~K}$ and $3.7 \mathrm{~K}$ when $\delta \varepsilon_{31}$ is 0.01 and 0.02 , respectively. The LST sensitivity also slightly depends on the land cover type, but such dependence appears to vary with atmospheric conditions. In addition, the VZA has slight influences on the LST sensitivities.

The channel 32 emissivity has much lower influence on the LST error compared with the channel 31 emissivity. For the BG0314 profile, $\delta T_{\mathrm{s}}$ is up to $0.8 \mathrm{~K}$ and $2.2 \mathrm{~K}$ when $\delta \varepsilon_{32}$ is up to 0.01 and 0.02 , while for the YK0707 profile, $\delta T_{\mathrm{s}}$ is up to $2.4 \mathrm{~K}$. Therefore, it can be concluded that the LST sensitivities on the LSEs rely on the atmospheric conditions. The proposed RM-GA method is much more sensitive to LSE errors under conditions with humid atmospheres than with dry atmospheres. This fact may be attributed to worse performances of the regression models under such conditions. Fortunately, we find that the varying trends of LST errors caused by emissivities in channels 31 and 32 are opposite. Therefore, the requirement for accurate LSEs in the RM-GA method is reduced.

The sensitivities of the proposed RM-GA method to $\delta T_{\mathrm{b} 31}$ and $\delta\left(T_{\mathrm{b} 31}-T_{\mathrm{b} 32}\right)$ are negligible. $\delta T_{\mathrm{s}}$ on $\delta T_{\mathrm{b} 31}$ and $\delta\left(T_{\mathrm{b} 31}-T_{\mathrm{b} 32}\right)$ calculated based on Equation (13) are zero. In addition, such sensitivity is independent of the atmospheric condition, land cover type, and VZA. 
Table 6. Land surface temperature (LST) error caused by errors in the LSEs of MODIS channels 31 and 32 for radiosonde profile BG0314.

\begin{tabular}{|c|c|c|c|c|c|c|c|c|}
\hline \multirow{2}{*}{$\begin{array}{c}\text { LSE } \\
\text { Error }\end{array}$} & \multicolumn{4}{|c|}{ LST Error Caused by $\delta \varepsilon_{31}$} & \multicolumn{4}{|c|}{ LST Error Caused by $\delta \varepsilon_{32}$} \\
\hline & $\begin{array}{c}\text { Soil, } \\
\text { VZA = }\end{array}$ & $\begin{array}{c}\text { Soil, } \\
\mathrm{VZA}=\mathbf{3 0}\end{array}$ & $\begin{array}{c}\text { Vegetation, } \\
\text { VZA = }\end{array}$ & $\begin{array}{c}\text { Vegetation, } \\
\mathrm{VZA}=\mathbf{3 0}\end{array}$ & $\begin{array}{c}\text { Soil, } \\
\text { VZA = }\end{array}$ & $\begin{array}{c}\text { Soil, } \\
\mathrm{VZA}=\mathbf{3 0}\end{array}$ & $\begin{array}{c}\text { Vegetation, } \\
\text { VZA = }\end{array}$ & $\begin{array}{c}\text { Vegetation, } \\
\mathrm{VZA}=\mathbf{3 0}\end{array}$ \\
\hline-0.010 & 1.4 & 1.3 & 1.2 & 1.2 & 0.8 & 0.8 & 0.6 & 0.6 \\
\hline-0.008 & 1.1 & 1.1 & 0.9 & 0.9 & 0.6 & 0.6 & 0.5 & 0.5 \\
\hline-0.006 & 0.8 & 0.8 & 0.7 & 0.7 & 0.5 & 0.5 & 0.3 & 0.3 \\
\hline-0.004 & 0.5 & 0.5 & 0.5 & 0.5 & 0.3 & 0.3 & 0.2 & 0.2 \\
\hline-0.002 & 0.3 & 0.3 & 0.2 & 0.2 & 0.1 & 0.1 & 0.1 & 0.1 \\
\hline 0.0 & 0.0 & 0.0 & 0.0 & 0.0 & 0.0 & 0.0 & 0.0 & 0.0 \\
\hline 0.002 & 0.3 & 0.3 & 0.2 & 0.2 & 0.1 & 0.1 & 0.1 & 0.1 \\
\hline 0.004 & 0.5 & 0.5 & 0.5 & 0.5 & 0.3 & 0.3 & 0.2 & 0.2 \\
\hline 0.006 & 0.8 & 0.8 & 0.7 & 0.7 & 0.4 & 0.4 & 0.3 & 0.3 \\
\hline 0.008 & 1.1 & 1.1 & 0.9 & 0.9 & 0.5 & 0.5 & 0.4 & 0.4 \\
\hline 0.010 & 1.4 & 1.4 & 1.2 & 1.2 & 0.6 & 0.6 & 0.5 & 0.5 \\
\hline
\end{tabular}

Table 7. LST error caused by errors in the LSEs of MODIS channels 31 and 32 for radiosonde profile YK0707.

\begin{tabular}{|c|c|c|c|c|c|c|c|c|}
\hline \multirow{2}{*}{$\begin{array}{c}\text { LSE } \\
\text { Error }\end{array}$} & \multicolumn{4}{|c|}{ LST Error Caused by $\delta \varepsilon_{31}$} & \multicolumn{4}{|c|}{ LST Error Caused by $\delta \varepsilon_{32}$} \\
\hline & $\begin{array}{c}\text { Soil, } \\
\text { VZA = } 0\end{array}$ & $\begin{array}{c}\text { Soil, } \\
\mathrm{VZA}=\mathbf{3 0}\end{array}$ & $\begin{array}{c}\text { Vegetation, } \\
\text { VZA }=0\end{array}$ & $\begin{array}{c}\text { Vegetation, } \\
\mathrm{VZA}=\mathbf{3 0}\end{array}$ & $\begin{array}{c}\text { Soil, } \\
\text { VZA }=0\end{array}$ & $\begin{array}{c}\text { Soil, } \\
\mathrm{VZA}=\mathbf{3 0}\end{array}$ & $\begin{array}{c}\text { Vegetation, } \\
\text { VZA }=0\end{array}$ & $\begin{array}{c}\text { Vegetation, } \\
\mathrm{VZA}=\mathbf{3 0}\end{array}$ \\
\hline-0.010 & 2.0 & 1.9 & 2.1 & 1.9 & 1.8 & 2.0 & 1.8 & 2.3 \\
\hline-0.008 & 1.6 & 1.5 & 1.7 & 1.6 & 1.7 & 2.2 & 1.9 & 2.4 \\
\hline-0.006 & 1.3 & 1.2 & 1.3 & 1.2 & 1.9 & 2.3 & 2.0 & 1.3 \\
\hline-0.004 & 0.9 & 0.8 & 0.9 & 0.8 & 0.9 & 0.7 & 2.2 & 0.7 \\
\hline-0.002 & 0.4 & 0.4 & 0.5 & 0.4 & 0.4 & 0.3 & 0.4 & 0.3 \\
\hline 0.0 & 0.0 & 0.0 & 0.0 & 0.0 & 0.0 & 0.0 & 0.0 & 0.0 \\
\hline 0.002 & 0.5 & 0.4 & 0.5 & 0.5 & 0.3 & 0.3 & 0.3 & 0.3 \\
\hline 0.004 & 1.1 & 1.1 & 1.2 & 1.0 & 0.6 & 0.5 & 0.6 & 0.6 \\
\hline 0.006 & 2.2 & 1.6 & 2.3 & 1.5 & 0.8 & 0.8 & 0.9 & 0.8 \\
\hline 0.008 & 2.5 & 2.7 & 2.7 & 2.8 & 1.1 & 1.0 & 1.1 & 1.0 \\
\hline 0.010 & 2.7 & 2.9 & 2.8 & 3.1 & 1.3 & 1.2 & 1.4 & 1.2 \\
\hline
\end{tabular}

\subsection{Validations}

The following three datasets are selected to evaluate the accuracy of the proposed RM-GA method: (1) simulation datasets based on in situ radiosonde profiles and GDAS profiles; (2) in situ measurements of LST in the field experiment; and (3) the daily MODIS LST products. Details can be found in the following sub-sections.

\subsubsection{Validation with Simulation Datasets}

The simulated at-sensor radiances of MODIS channels 31 and 32 based on the eighteen radiosonde profiles collected in the field experiment are used to retrieve the LST through the proposed RM-GA. 
A scatter plot relating the estimated LSTs and the input LSTs to the MODTRAN4 code for all radiosonde profiles is displayed in Figure 5. It is evident that most of the samples are close to the 1:1 line. The calculated RMSE and MAE for all the samples are $0.9 \mathrm{~K}$ and $0.7 \mathrm{~K}$, respectively. The dependence of the retrieval error on the sensor view zenith angle is weak, thus indicating that the RM-GA method can obtain a similar accuracy at large and small view angles.

Figure 5. Scatter plot between the estimated LST and the LST input to the MODTRAN4 code for the eighteen radiosonde profiles. The solid line corresponds to a 1:1 relation.

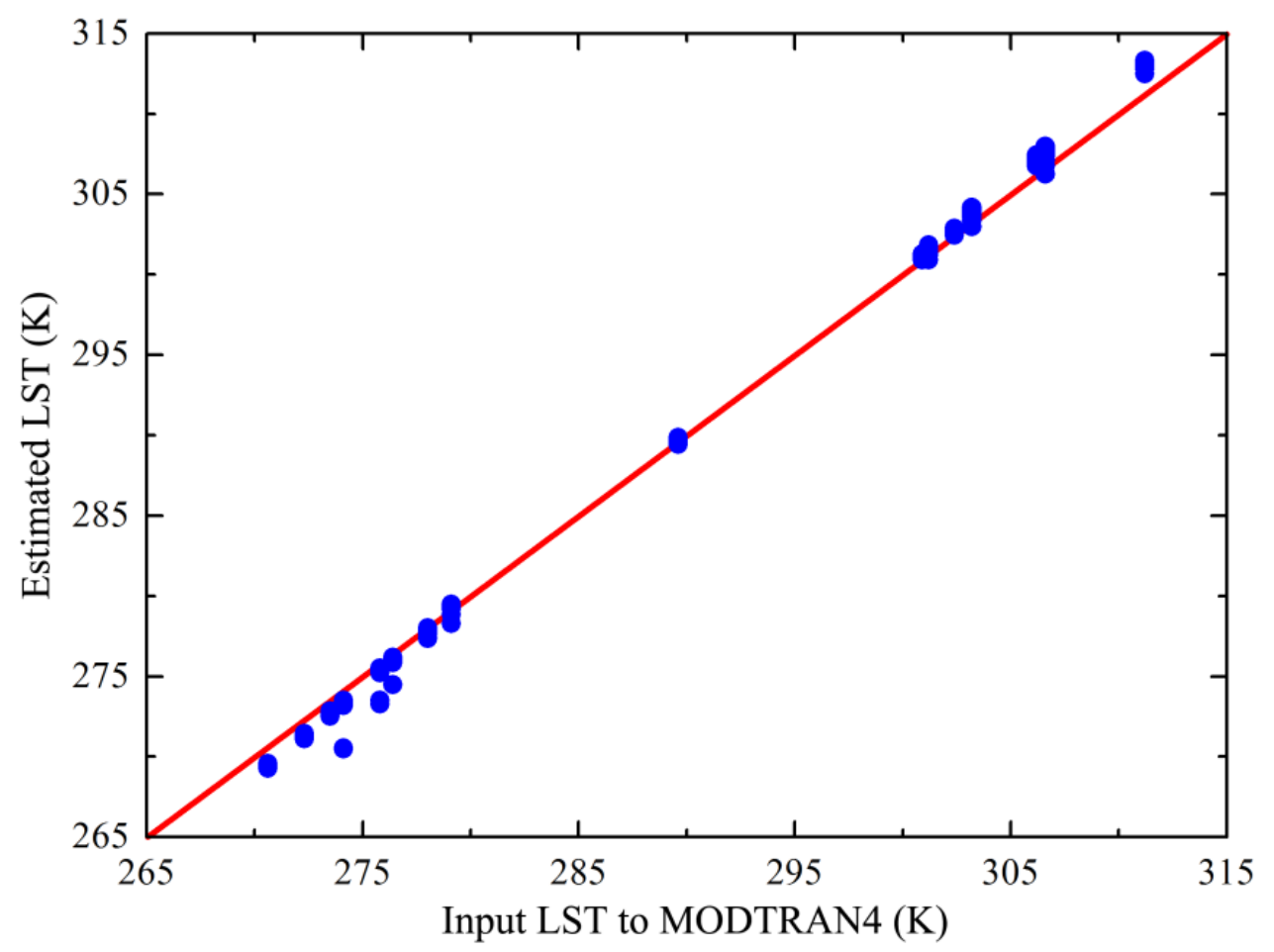

In addition, the simulated at-sensor radiances of MODIS channels 31 and 32, based on the GDAS profiles, are placed into the RM-GA method to estimate the LST. The details are shown in Table 8. The RMSEs of these four grids range from $0.7 \mathrm{~K}$ to $1.0 \mathrm{~K}$, and the MAEs range from $0.5 \mathrm{~K}$ to $0.8 \mathrm{~K}$. The overall MAE and RMSE for all the profiles are $0.6 \mathrm{~K}$ and $0.9 \mathrm{~K}$, respectively.

Table 8. Validation of the RM-GA method with simulations of GDAS profiles in the study area.

\begin{tabular}{cccc}
\hline Grid Location & Sample Size & MAE $(\mathbf{K})$ & RMSE $(\mathbf{K})$ \\
\hline$\left(100^{\circ} \mathrm{E}, 38^{\circ} \mathrm{N}\right)$ & 1495 & 0.8 & 1.0 \\
$\left(100^{\circ} \mathrm{E}, 39^{\circ} \mathrm{N}\right)$ & 1339 & 0.5 & 0.7 \\
$\left(98^{\circ} \mathrm{E}, 40^{\circ} \mathrm{N}\right)$ & 1326 & 0.6 & 0.8 \\
$\left(99^{\circ} \mathrm{E}, 40^{\circ} \mathrm{N}\right)$ & 1326 & 0.6 & 0.8 \\
Total & 5486 & 0.6 & 0.9 \\
\hline
\end{tabular}

\subsubsection{Validation with In Situ LST Measurements}

The in situ measured LSTs described in Section 2.1 are also used to validate the proposed RM-GA method. The measured and retrieved LSTs are listed in Table 9. The LSTs of the two key areas 
extracted from the daily MODIS LST/emissivity products (i.e., MOD11A1 and MYD11A1) in version V005 are also shown for comparison purposes. The MAE and RMSE for the LSTs retrieved using our method are $0.9 \mathrm{~K}$ and $1.0 \mathrm{~K}$, respectively. The MAE and RMSE for the LSTs provided by the MODIS LST/emissivity products are $0.9 \mathrm{~K}$ and $1.1 \mathrm{~K}$, respectively. Comparisons of the two key areas demonstrate that the proposed RM-GA method is accurate for actual MODIS images for the study area.

Table 9. Comparisons of the LSTs provided by the in situ measurements, the RM-GA method and the daily MODIS LST/emissivity products.

\begin{tabular}{ccccc}
\hline Satellite & Location & Measured LST (K) & Estimated LST by RM-GA (K) & MODIS product (K) \\
\hline \multirow{2}{*}{ Terra } & $100.98^{\circ} \mathrm{E}, 38.22^{\circ} \mathrm{N}$ & 292.2 & 291.5 & 290.2 \\
& $100.97^{\circ} \mathrm{E}, 38.26^{\circ} \mathrm{N}$ & 291.7 & 290.3 & 290.7 \\
\hline \multirow{2}{*}{ Aqua } & $100.98^{\circ} \mathrm{E}, 38.22^{\circ} \mathrm{N}$ & 294.2 & 294.0 & 294.4 \\
& $100.97^{\circ} \mathrm{E}, 38.26^{\circ} \mathrm{N}$ & 294.3 & 293.1 & 294.1 \\
\hline
\end{tabular}

\subsubsection{Comparisons with MODIS LST Products}

LSTs retrieved with the RM-GA method are further compared with those extracted from MOD11A1 LST/emissivity products, which yield $1.0 \mathrm{~K}$ accuracy for surfaces with known emissivities [54]. The selected MODIS images were acquired by Terra MODIS at 04:05 and 15:10 (UTC) on 6 July 2007. A region covering part of the study area under clear-sky conditions was selected. The images were acquired in the summer, when the atmosphere in the study area is relatively humid and warm. Therefore, it is a typical data source to test our method.

The land surface emissivities of MODIS channels 31 and 32 that are necessary for the proposed method are calculated according to [55]. In general, the spatial patterns of LSTs derived from the RM-GA method and MODIS LST products are similar (Figure 6): the gobis and deserts exhibited high surface temperatures, vegetation such as croplands and meadows yielded moderate temperatures, and the partly snow-covered mountains in the southern part of the region were the coldest. The temperature ranges for the entire region derived from both methods are similar. For our method, the LST ranges were $270.5 \mathrm{~K}$ to $330.0 \mathrm{~K}$ and $262.2 \mathrm{~K}$ to $297.2 \mathrm{~K}$ at $04: 05$ and $15: 10$, respectively. The LST ranges derived from MODIS LST products were $271.2 \mathrm{~K}$ to $330.9 \mathrm{~K}$ and $262.3 \mathrm{~K}$ to $296.0 \mathrm{~K}$, respectively. Comparisons reveal that $89.7 \%$ of all the pixels had a $-1.0 \mathrm{~K}$ to $2.0 \mathrm{~K}$ deviation from the MODIS LST/emissivity product for the daytime image, whereas $91.5 \%$ of all the pixels yielded a $-1.0 \mathrm{~K}$ to 3.0 K deviation from the MODIS product for the nighttime image.

The LST estimations based on the RM-GA method were slightly higher than those provided by the MODIS products for many pixels. The positive deviation of the LSTs estimated by our method from those provided by the MODIS products might result from the replacement of the atmospheric downwelling radiances with the atmospheric upwelling radiances in the RTEs because the atmospheric downwelling radiance in MODIS channel 31 or channel 32 is higher than the atmospheric upwelling radiance in the corresponding channel. 
Figure 6. Spatial patterns of the land surface temperature in the study area retrieved by the RM-GA method and those provided by MODIS LST/emissivity products. A is vegetation, B is snow, C is gobi, and D is desert. The MODIS images were acquired on 6 July 2007. (a) LST at 04:05UTC retrieved with the RM-GA method. (b) LST at 04:05UTC provided by the MODIS LST/emissivity product. (c) LST at 15:10UTC retrieved with the RM-GA method. (d) LST at 15:10UTC provided by the MODIS LST/emissivity product.
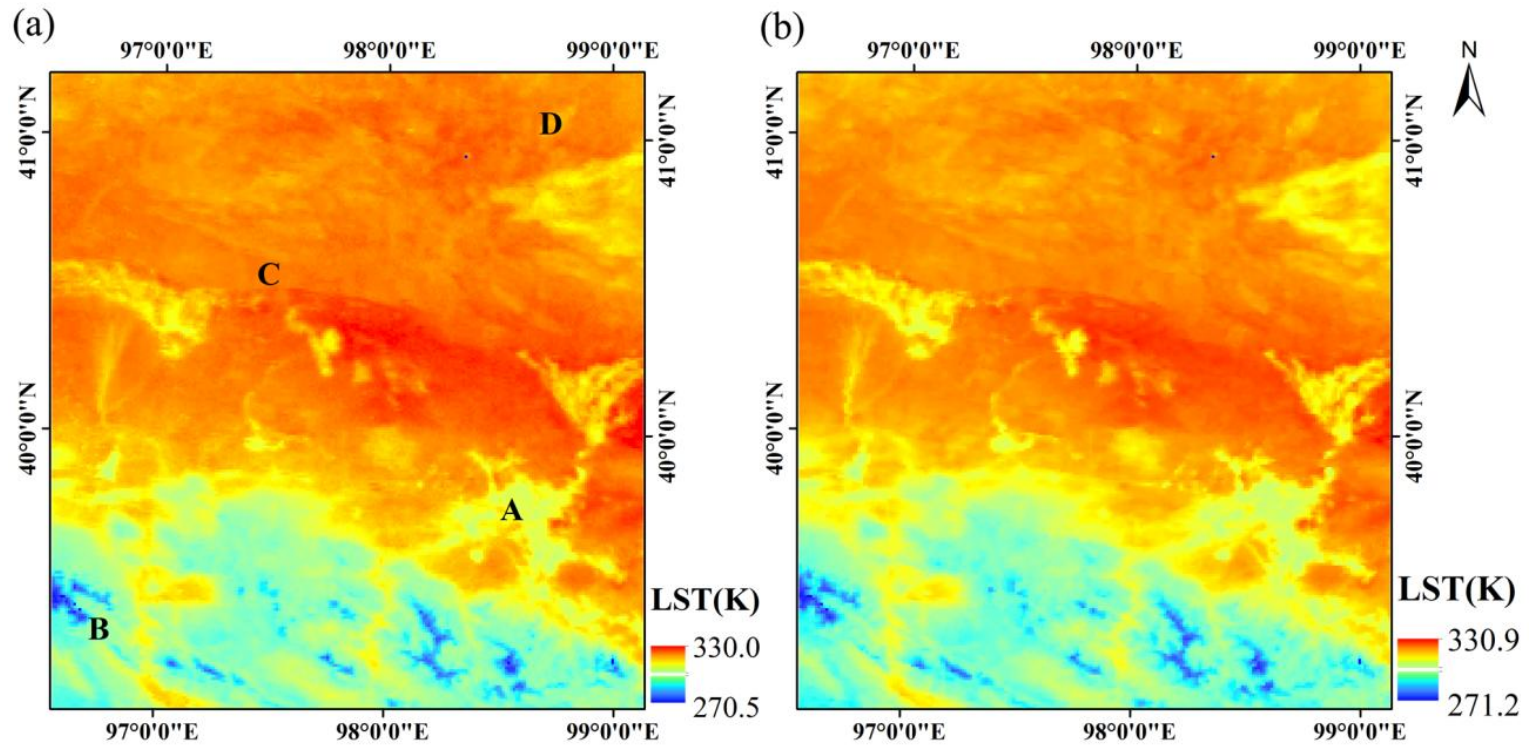

(c)

$98^{\circ} 0^{\prime} 0 " \mathrm{E}$

(d)
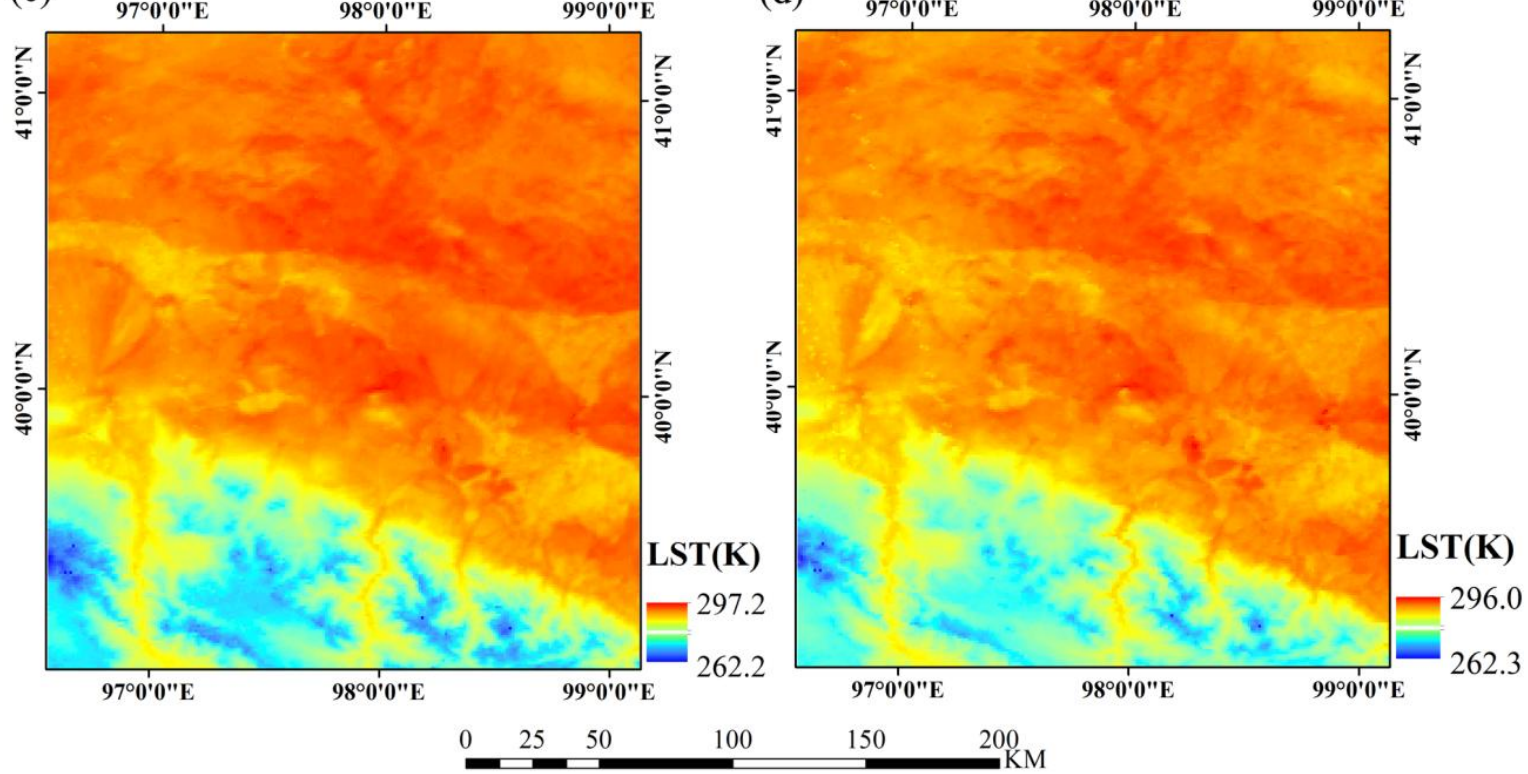

\section{Discussion}

Developing split-window (SW) algorithms for estimating LSTs from thermal sensors with two or more channels in the range of 10-12 $\mu \mathrm{m}$ has been a hot topic in the remote sensing domain over the past several decades. Some of these SW algorithms can provide accurate and stable LSTs, such as the generalized SW algorithm for generating the MODIS LST/emissivity products [15]. In addition to the LSE, many SW algorithms rely on other auxiliary parameters, e.g., the atmospheric water vapor 
content. The similarities of spectral responses of the thermal channels stimulate us to attempt to reduce the unknowns when solving the radiative transfer equations.

Although there have been numerous algorithms proposed by literatures for deriving LSTs from MODIS data, MODIS is still selected as a test case to develop the RM-GA method because MODIS has excellent calibration accuracy, friendly preprocessing tools and recognized land surface products. Its LST/emissivity product is beneficial for validating the RM-GA method. However, the proposed method is not limited to MODIS and can easily be extended to other satellite thermal sensors with similar channels as MODIS channels 31 and 32. For example, the spectral range of AVHRR channels 4 and 5 are approximately 10.0 to $11.5 \mu \mathrm{m}$ and 11.5 to $12.5 \mu \mathrm{m}$, respectively. The ASTER sensor on board Terra satellite has two similar channels in the previous spectral range, i.e., channel 13 from 10.25 to $10.95 \mu \mathrm{m}$ and channel 14 from 10.95 to $11.65 \mu \mathrm{m}$. These two channels have been proven reliable for estimating LSTs with the split-window algorithm [56]. In addition, the Thermal Infrared Sensor (TIRS) carried by the Landsat- 8 satellite (launched as the Landsat Data Continuity Mission-LDCM- on 11 February 2013) also obtains two similar channels. The wavelengths of the first and second channels are $10.6 \mu \mathrm{m}$ to $11.19 \mu \mathrm{m}$ and $11.5 \mu \mathrm{m}$ to $12.51 \mu \mathrm{m}$, respectively. With the simulation dataset generated based on GDAS atmospheric profiles in the study area, we find that the regression models for the previously mentioned sensors have the following general form:

$$
\left[\begin{array}{c}
\tau_{1}\left(L_{1}^{\uparrow}\right) \\
\tau_{2}\left(L_{1}^{\uparrow}\right) \\
L_{2}^{\uparrow}\left(L_{1}^{\uparrow}\right)
\end{array}\right]=\left[\begin{array}{lll}
a_{11} & a_{12} & a_{13} \\
a_{21} & a_{22} & a_{23} \\
a_{31} & a_{32} & a_{33}
\end{array}\right]\left[\begin{array}{c}
L_{1}^{\uparrow 2} \\
L_{1}^{\uparrow} \\
1
\end{array}\right]
$$

where $a_{i j}$ is the coefficient ( $i=1,2$, and $3 ; j=1,2$, and 3); the subscripts 1 and 2 denote the first and second channels described previously. The coefficients are listed in Table 10.

In this research, the RM-GA method is proposed for local application in the Heihe River basin, which has an arid climate with low atmospheric water vapor content. The atmospheric effects in the study area are weaker than those in humid regions. The correlations between atmospheric parameters decrease when the atmospheric water vapor content increases [25]. Our research confirms this finding. Accuracies of the regression models decrease when the atmospheric upwelling radiance increases. This phenomenon may increase the error of the retrieved LST. Thus, the applicability of the proposed method to regions with a humid atmosphere is limited. However, it is feasible to extend the proposed method to regions with arid climates and high elevations, e.g., the Qinghai-Tibet Plateau, the Sahara Desert and the Middle East. It is critical that these regions are ecologically vulnerable, and they require satellite LSTs in monitoring the climate changes and in other applications.

In addition to the LST, the RM-GA method provides a possible way to estimate the atmospheric upwelling radiance from the thermal infrared data. To our knowledge, the atmospheric upwelling radiance is an important parameter in atmospheric corrections. Therefore, the RM-GA method may benefit the removal of atmospheric path radiance from thermal data. This preprocessing is required by some other methods, such as the TES algorithms.

The development of the RM-GA method is based on some important assumptions or simplifications. The first is that the land is a Lambertian surface. Therefore, a commonly used simplified radiative transfer equation is used. In fact, many land surfaces are far from Lambertian bodies, and their 
emission and reflection varies with the zenith and azimuth viewing angles. This thermal anisotropy effect is another key question related to thermal remote sensing. Detailed models are still necessary to examine and model the thermal anisotropy effect thoroughly. Another simplification is that the aerosol condition of the study area has been assumed stable when conducting the radiative transfer simulations. In fact, the aerosol influences the atmospheric transmittance [57]. A larger simulation dataset containing different aerosol conditions might be better than the current one used in this research.

Table 10. Coefficient in Equation (14) for AVHRR, ASTER, and TIRS sensors derived from the simulation dataset generated based on GDAS atmospheric profiles.

\begin{tabular}{|c|c|c|c|c|c|}
\hline $\begin{array}{c}\text { Satellite and } \\
\text { Sensor }\end{array}$ & $a_{i 1}(i=1,2,3)$ & $a_{i 2}(i=1,2,3)$ & $a_{i 3}(i=1,2,3)$ & Adjusted $R^{2}$ & $\begin{array}{c}\text { Standard Error } \\
\text { of Estimate }\end{array}$ \\
\hline \multirow{3}{*}{ NOAA-7 AVHRR } & 0 & -0.134 & 0.987 & 0.989 & 0.0097 \\
\hline & 0 & -0.181 & 0.981 & 0.986 & 0.0150 \\
\hline & -0.073 & 1.460 & -0.035 & 0.999 & 0.0290 \\
\hline \multirow{3}{*}{ NOAA-9 AVHRR } & 0 & -0.134 & 0.987 & 0.989 & 0.0096 \\
\hline & 0 & -0.178 & 0.985 & 0.986 & 0.0147 \\
\hline & -0.060 & 1.411 & -0.046 & 0.999 & 0.0330 \\
\hline \multirow{3}{*}{ NOAA-11 AVHRR } & 0 & -0.134 & 0.987 & 0.989 & 0.0097 \\
\hline & 0 & -0.180 & 0.983 & 0.986 & 0.0150 \\
\hline & -0.067 & 1.436 & -0.039 & 0.999 & 0.0302 \\
\hline \multirow{3}{*}{ NOAA-12 AVHRR } & 0 & -0.135 & 0.987 & 0.989 & 0.0098 \\
\hline & 0 & -0.181 & 0.976 & 0.986 & 0.0150 \\
\hline & -0.081 & 1.482 & -0.019 & 0.999 & 0.0240 \\
\hline \multirow{3}{*}{ NOAA-14 AVHRR } & 0 & -0.134 & 0.987 & 0.989 & 0.0097 \\
\hline & 0 & -0.186 & 0.976 & 0.985 & 0.0160 \\
\hline & -0.088 & 1.531 & -0.025 & 0.999 & 0.0298 \\
\hline \multirow{3}{*}{ Terra ASTER } & 0 & -0.133 & 0.986 & 0.989 & 0.0095 \\
\hline & 0 & -0.156 & 0.996 & 0.984 & 0.0132 \\
\hline & 0 & 1.132 & -0.053 & 0.997 & 0.0397 \\
\hline \multirow{3}{*}{ Landsat-8 TIRS } & 0 & -0.135 & 0.984 & 0.988 & 0.0105 \\
\hline & 0 & -0.175 & 0.991 & 0.987 & 0.0143 \\
\hline & -0.030 & 1.299 & -0.071 & 0.999 & 0.0309 \\
\hline
\end{tabular}

The accuracies of LSEs have great effects on the performance of the RM-GA method, as proven in the sensitivity analysis. Therefore, the RM-GA method relies on accurate determinations of LSEs. Determinations of LSEs in the thermal channels can be conducted with the commonly used Normalized Difference Vegetation Index Thresholds Method $\left(\mathrm{NDVI}^{\mathrm{THM}}\right)$ or Classification-based Emissivity Method (CBEM) with good accuracies, e.g., approximately 0.02 for the former method [58]. However, the emissivities of bare soil are still difficult to determine. Fortunately, we found that the errors of emissivities in MODIS channels 31 and 32 have opposite impacts on the LST errors. Therefore, the rigorous requirement for accurate emissivities in the RM-GA method may be partially mitigated.

Validation of the LST retrieval methods is an important step for developing algorithms and guarantees the application of such methods. However, such validation is a difficult task and is influenced by many factors. In our previous research on validating the Landsat-5 TM LSTs with 
surface measurements, we found that deviations of the retrieved LSTs from the measured values might be attributed to the following sources [59]: errors in the in situ measurement of the LST, the measurement accuracy of the instruments and errors caused by their calibrations, the scale mismatch between pixels on the remote sensing image and the sampled LSTs, errors in the retrieved results due to a lack of in situ measured land surface emissivities, and the calibration of satellite sensors. Further comprehensive validations are still required to quantify the accuracies of the estimated LSTs based on remote sensing.

\section{Conclusions}

Many split-window (SW) algorithms require auxiliary atmospheric parameters (e.g., water vapor content) to calculate land surface temperatures (LSTs) from satellite sensors with two adjacent thermal channels located in the atmospheric window between $10 \mu \mathrm{m}$ and $12 \mu \mathrm{m}$. In this research, the Heihe River basin, which is one of the most arid regions in China and consistently has low atmospheric water vapor content, was selected as the study area. For the study area, we found that correlations between the atmospheric parameters of two adjacent channels provide the possibility to reduce the unknowns when calculating the LST by solving the radiative transfer equations.

MODIS was selected as a test case to develop a so-called regression model—genetic algorithm (RM-GA)-based method because MODIS has excellent calibration accuracy, friendly preprocessing tools, and recognized land surface products. To develop the RM-GA method, the Global Data Assimilation System (GDAS) atmospheric profiles of the study area were used to generate the training dataset through radiative transfer simulation. The relationships between the atmospheric upwelling radiance in MODIS channel 31 and the other three atmospheric parameters, including the transmittance in channel 31 and the transmittance and upwelling radiance in channel 32, were trained based on the simulation dataset and formulated with three regression models. The genetic algorithm was used to estimate the LST.

Validation of the RM-GA method included three aspects. First, validation was performed through the simulations of in situ radiosonde profiles and GDAS atmospheric profiles based on MODTRAN4 code. The accuracy of our method was better than $1.0 \mathrm{~K}$ when there was no LSE error. Second, the in situ LSTs measured in the study area were used to assess the proposed method. We found that its accuracy was close to that of the daily MODIS LST/emissivity (MOD11A1) products. Third, a pair of daytime and nighttime MOD11A1 products covering the study area in summer was used as a reference to evaluate the LSTs estimated through the RM-GA method. The comparisons further confirmed that the proposed method is able to provide acceptable estimations of LSTs from MODIS data in the study area. Although this research is for local application in the Heihe River basin, the findings and proposed method can easily be extended to other satellite sensors and regions with arid climates and high elevations.

\section{Acknowledgments}

This work is supported in part by the Chinese State Key Basic Research Project (Grant No. 2013CB733406), by the National High Technology Research and Development Program of China (Grant No. 2013AA122801), by the National Natural Science Foundation of China 
(Grant No. 41101380 and 41371341), and by the Opening Funding of State Key Laboratory for Remote Sensing Science (Grant No. OFSLRSS201313). The in situ measured radiosonde profiles and land surface temperatures were provided by the Watershed Allied Telemetry Experimental Research (WATER). We thank the anonymous referees for their constructive criticism and comments.

\section{Author Contributions}

Ji Zhou wrote the manuscript and was responsible for research design, data preparation and processing, and analysis. Xu Zhang contributed significantly to the radiative transfer simulation and validation. Wenfeng Zhan wrote the Matlab programs for the method proposed in this research and provided constructive comments and suggestions for developing the method. Huailan Zhang contributed to the sensitivity analysis part and made the maps in this paper.

\section{Conflicts of Interest}

The authors declare no conflict of interest.

\section{References}

1. Li, Z.L.; Tang, B.H.; Wu, H.; Ren, H.; Yan, G.; Wan, Z.; Trigo, I.F.; Sobrino, J.A. Satellite-derived land surface temperature: Current status and perspectives. Remote Sens. Environ. 2013, 131, 14-37.

2. Zhou, J.; Chen, Y.H.; Wang, J.F.; Zhan, W.F. Maximum nighttime Urban Heat Island (UHI) intensity simulation by integrating remotely sensed data and meteorological observations. IEEE J. Sel. Topics Appl. Earth Observ. 2011, 4, 138-146.

3. Qin, Z.H.; Karnieli, A. Progress in the remote sensing of land surface temperature and ground emissivity using NOAA-AVHRR data. Int. J. Remote Sens. 1999, 20, 2367-2393.

4. Prata, A.J. Land surface temperatures derived from the advanced very high resolution radiometer and the along-track scanning radiometer: 1. Theory. J. Geophys. Res. 1993, 98, 16689-16702.

5. Snyder, W.C.; Wan, Z.; Zhang, Y.; Feng, Y.Z. Classification-based emissivity for land surface temperature measurement from space. Int. J. Remote Sens. 1998, 19, 2753-2774.

6. Kealy, P.S.; Hook, S.J. Separating temperature and emissivity in thermal infrared multispectral scanner data: Implications for recovering land surface temperatures. IEEE Trans. Geosci. Remote Sens. 1993, 31, 1155-1164.

7. Gillespie, A.; Rokugawa, S.; Matsunaga, T.; Cothern, J.S.; Hook, S.; Kahle, A.B. A temperature and emissivity separation algorithm for Advanced Spaceborne Thermal Emission and Reflection Radiometer (ASTER) images. IEEE Trans. Geosci. Remote Sens. 1998, 36, 1113-1126.

8. Liang, S.L. An optimization algorithm for separating land surface temperature and emissivity from multispectral thermal infrared imagery. IEEE Trans. Geosci. Remote Sens. 2001, 39, 264-274.

9. Valor, E.; Caselles, V. Mapping land surface emissivity from NDVI: Application to European, African, and South American areas. Remote Sens. Environ. 2001, 57, 167-184.

10. Ottlé, C.; Vidal-Madjar, D. Estimation of land surface temperature with NOAA-9 data. Remote Sens. Environ. 1992, 40, 27-41. 
11. François, C.; Ottlé, C. Atmospheric corrections in the thermal infrared: Global and water vapor dependent split-window algorithms-Applications to ATSR and AVHRR data. IEEE Trans. Geosci. Remote Sens. 1996, 34, 457-470.

12. Price, J.C. Land surface temperature measurements from the split window channels of the NOAA7 advanced very high resolution radiometer. J. Geophys. Res. 1984, 89, 7231-7237.

13. Ulivieri, C.; Cannizzaro, G. Land surface temperature retrievals from satellite measurements. Acta Astronaut. 1985, 12, 977-985.

14. Becker, F.; Li, Z. Towards a local split window method over land surfaces. Int. J. Remote Sens. 1990, 11, 369-393.

15. Wan, Z.; Dozier, J. A generalized split-window algorithm for retrieving land-surface temperature from space. IEEE Trans. Geosci. Remote Sens. 1996, 34, 892-905.

16. Prata, A.J.; Platt, C.M.R. Land Surface Temperature Measurements from the AVHRR. In Proceedings of the 5th AVHRR Data Users Conference, Tromso, Norway, 25-28 June 1991; pp. 433-438.

17. Vidal, A. Atmospheric and emissivity correction of land surface temperature measured from satellite using ground measurements or satellite data. Int. J. Remote Sens. 1991, 12, 2449-2460.

18. Ulivieri, C.; Castronuovo, M.M.; Francioni, R; Cardillo, A. A split window algorithm for estimating land surface temperature from satellites. Adv. Space Res. 1994, 14, 59-65.

19. Sobrino, J.A.; Coll, C.; Casselles, V. Atmospheric corrections for land surface temperature using AVHRR channels 4 and 5. Remote Sens. Environ. 1991, 38, 19-34.

20. Coll, C.; Caselles, V.; Sobrino, J.A.; Valor, E. On the atmospheric dependence of the split-window equation for land surface temperature. Int. J. Remote Sens. 1994, 15, 105-122.

21. Sobrino, J.A.; Raissouni, N. Toward remote sensing methods for land cover dynamic monitoring: Application to Morocco. Int. J. Remote Sens. 2000, 21, 353-366.

22. Ma, Y. Remote sensing parameterization of regional net radiation over heterogeneous land surface of Tibetan Plateau and arid area. Int. J. Remote Sens. 2003, 24, 3137-3148.

23. Becker, F.; Li, Z. Surface temperature and emissivity at various scales: Definition, measurement and related problems. Remote Sens. Rev. 1995, 12, 225-253.

24. Jiménez-Muñoz, J.C.; Sobrino, J.A. A generalized single-channel method for retrieving land surface temperature from remote sensing data. J. Geophys. Res. 2003, 108, doi:10.1029/2003JD003480.

25. Jiménez-Muñoz, J.C.; Cristóbal, J.; Sobrino, J.A.; Soria, G. Revision of the single-channel algorithm for land surface temperature retrieval from Landsat thermal-infrared data. IEEE Trans. Geosci. Remote Sens. 2009, 47, 339-349.

26. Chrysoulakis, N.; Cartalis, C. Improving the estimation of land surface temperature for the region of Greece: Adjustment of a split window algorithm to account for the distribution of precipitable water. Int. J. Remote Sens. 2002, 23, 871-880.

27. Zhao, S.; Qin, Q.; Yang, Y.; Xiong, Y.; Qiu, G. Comparison of two split-window methods for retrieving land surface temperature from MODIS data. J. Earth Syst. Sci. 2009, 118, 345-353.

28. Yang, J.M.; Qiu, J.H. The empirical expressions of the relation between precipitable water and ground water vapor pressure for some areas in China. Sci. Atmos. Sin. 1996, 20, 620-626.

29. Yang, J.M.; Qiu, J.H. A method for estimating precipitable water and effective water vapor content from ground humidity parameters. Chin. J. Atmos. Sci. 2002, 26, 9-22. 
30. Li, Z.H.; Muller, J.P.; Cross, P. Comparison of precipitable water vapor derived from radiosonde, GPS, and moderate-resolution imaging spectroradiometer measurements. J. Geophys. Res. 2003, 108, doi:10.1029/2003JD003372.

31. Jedlovec, G.J. Precipitable water estimation from high-resolution split window radiance measurements. J. Appl. Meteorol. 1990, 29, 863-877.

32. Kaufman, Y.J.; Gao, B.C. Remote sensing of water vapor in the near IR from EOS/MODIS. IEEE Trans. Geosci. Remote Sens. 1992, 30, 871-884.

33. Moriyama, M.; Mima, K.; Arai, K. Comparison of the sea surface temperature estimation methods. Adv. Space Res. 1995, 16, 123-126.

34. Wang, K.L.; Cheng, G.D.; Jiang, H.; Zhang, L.J. Atmospheric hydrologic cycle over the Qilian-Heihe valley. Adv. Water Sci. 2003, 14, 91-97.

35. Hu, Y.Q. Research advance about the energy budget and transportation of water vapor in the HEIFE area. Adv. Earch Sci. 1994, 9, 30-34.

36. Li, X.; Li, X.W.; Li, Z.Y.; Ma, M.G.; Wang, J.; Xiao, Q.; Liu, Q.; Che, T.; Chen, E.X.; Yan, G.J.; et al. Watershed Allied Telemetry Experimental Research. J. Geophys. Res. 2008, 114, doi:10.1029/2008JD011590.

37. Tonooka, H. An atmospheric correction algorithm for thermal infrared multispectral data over land-a water-vapor scaling method. IEEE Trans. Geosci. Remote Sens. 2001, 39, 682-692.

38. Dash, P.; Ignatov, A. Validation of clear-sky radiances over oceans simulated with MODTRAN4.2 and global NCEP GDAS fields against nighttime NOAA15-18 and MetOp-A AVHRR data. Remote Sens. Environ. 2008, 112, 3012-3029.

39. Hook, S.J.; Vaughan, R.G.; Tonooka, H.; Schladow, S.G. Absolute radiometric in-flight validation of mid infrared and thermal infrared data from ASTER and MODIS on the Terra spacecraft using the Lake Tahoe, CA/NV, USA, automated validation site. IEEE Trans. Geosci. Remote Sens. 2007, 45, 1798-1807.

40. Huang, M.; Liu, S.; Liu, S.; Zhu, Q. A study of the difference between true surface temperature and radiometric surface temperature. Adv. Earth Sci. 2005, 20, 1075-1082.

41. Berk, A.; Bernstein, L.S.; Anderson, G.P.; Acharya, P.K.; Robertson, D.C. MODTRAN cloud and multiple scattering upgrades wit application to AVIRIS. Remote Sens. Environ. 1998, 65, 367-375.

42. Dash, P.; Göttsche, F.M.; Olesen, F.S.; Fisch, H. Land surface temperature and emissivity estimation from passive sensor data: Theory and practice-current trends. Int. J. Remote Sens. 2002, 23, 2563-2594.

43. Ottlé, C.; Stoll, M. Effect of atmospheric absorption and surface emissivity on the determination of land surface temperature from infrared satellite data. Int. J. Remote Sens. 1993, 14, 2025-2037.

44. Zhou, J.; Chen, Y.; Zhang, X.; Zhan, W. Modeling the diurnal variations of urban heat islands with multi-source satellite data. Int. J. Remote Sens. 2013, 34, 7568-7588.

45. França, G.B.; Cracknell, A.P. Retrieval of land and sea surface temperature using NOAA-11 AVHRR data in northeastern Brazil. Int. J. Remote Sens. 1994, 15, 1695-1712.

46. Qin, Z.H.; Olmo, G.D.; Karnieli, A.; Berliner, P. Derivation of split window algorithm and its sensitivity analysis for retrieving land surface temperature from NOAA-advanced very high resolution radiometer data. J. Geophys. Res. 2001, 106, 22655-22670. 
47. Liang, S.L. Quantitative Remote Sensing of Land Surfaces; John Wiley \& Sons: Hoboken, NJ, USA, 2004.

48. Van Coillie, F.M.B.; Verbeke, L.P.C.; de Wulf, R.R. Feature selection by genetic algorithms in object-based classification of IKONOS imagery for forest mapping in Flanders, Belgium. Remote Sens. Environ. 2007, 110, 476-487.

49. Lei, Y.J.; Zhang, S.W.; Li, J.W.; Zhou, C.M. Matlab Toolbox for Genetic Algorithm and Its Application; Xidian University Press: Xi'an, China, 2005.

50. Xu, X.R.; Chen, L.F.; Zhuang, J.L. Genetic inverse algorithm for retrieval of component temperature of mixed pixel by multi-angle thermal infrared remote sensing data. Sci. China Ser. D 2001, 44, 363-372.

51. Zhuang, J.L.; Chen, L.F.; Xu, X.R. Retrieval of component temperature of continuous vegetation using genetic algorithm. J. Remote Sens. 2001, 5, 1-7.

52. Song, X.N.; Zhao, Y.S. Study on component temperatures inversion using satellite remotely sensed data. Int. J. Remote Sens. 2007, 28, 2567-2579.

53. Li, Z.; Becker, F. Feasibility of land surface temperature and emissivity determination from AVHRR data. Remote Sens. Environ. 1993, 43, 67-85.

54. Wan, Z. New refinements and validation of the MODIS land-surface temperature/emissivity products. Remote Sens. Environ. 2008, 112, 59-74.

55. Momeni, M.; Saradjian, M.R. Evaluating NDVI-based emissivities of MODIS bands 31 and 32 using emissivities derived by Day/Night LST algorithm. Remote Sens. Environ. 2007, 106, 190-198.

56. Pu, R.; Gong, P.; Michishita, R.; Sasagawa, T. Assessment of multi-resolution and multi-sensor data for urban surface temperature retrieval. Remote Sens. Environ. 2006, 104, 211-225.

57. Jiménez-Muñoz, J.C.; Sobrino, J.A. Error sources on the land surface temperature retrieved from thermal infrared single channel remote sensing data. Int. J. Remote Sens. 2006, 27, 999-1014.

58. Sobrino, J.A.; Raissouni, N.; Li, Z. A comparative study of land surface emissivity retrieval from NOAA data. Remote Sens. Environ. 2001, 75, 256-266.

59. Zhou, J.; Li, J.; Zhang, L.; Hu, D.; Zhan, W. Intercomparison of methods for estimating land surface temperature from a Landsat-5 TM image in an arid region with low water vapour in the atmosphere. Int. J. Remote Sens. 2012, 33, 2582-2602.

(C) 2014 by the authors; licensee MDPI, Basel, Switzerland. This article is an open access article distributed under the terms and conditions of the Creative Commons Attribution license (http://creativecommons.org/licenses/by/3.0/). 